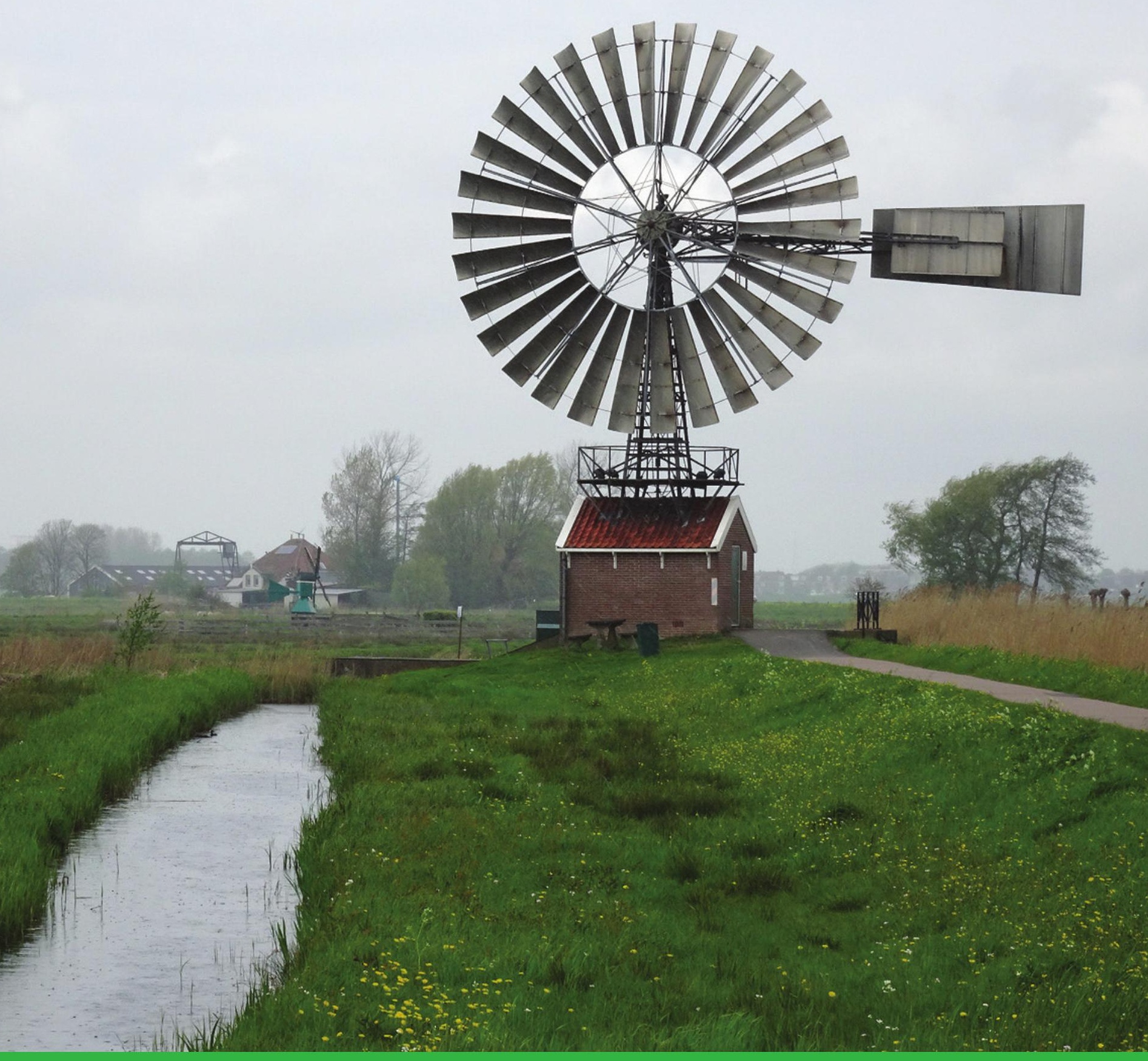

\title{
Transecten en meetpunten voor Meetnet Biodiversiteit Zaanstad
}





\section{Transecten en meetpunten voor Meetnet Biodiversiteit Zaanstad}

Fabrice Ottburg, Dennis Lammertsma en Rob Smidt 
Ottburg, F.G.W.A., D.R. Lammertsma en R. Smidt, 2018. Transecten en meetpunten voor Meetnet Biodiversiteit Zaanstad. Wageningen, Wageningen Environmental Research, Rapport 2885. 48 blz.; 29 fig.; 15 tab.; 2 ref.

Naar aanleiding van een motie van Groen Links binnen de gemeente Zaanstad, waarin het 'Monitoren van Biodiversiteit' als speerpunt staat gemeld, heeft Wageningen Environmental Research voor de gemeente Zaanstad onderzocht hoe biodiversiteit binnen de gemeentegrenzen kan worden gemeten en gevolgd. Deze bevindingen zijn eerder verschenen in WENR-rapport 2866, 'Meetnet Biodiversiteit Zaanstad'. In de voorliggende rapportage zijn op verzoek van de gemeente Zaanstad door Wageningen Environmental Research de monitoringtransecten voor de verschillende soorten, soortgroepen en habitattypen op kaart gezet, gerelateerd aan de 22 landschapstypen die in de gemeente Zaanstad zijn onderscheiden.

Trefwoorden: Biodiversiteit, Citizen Science, gemeente Zaanstad, Meetnet Biodiversiteit, Meetnet Biodiversiteit Zaanstad (MBZ), Meetpunten, Monitoringtransecten en Transecten

Dit rapport is gratis te downloaden van https://doi.org/10.18174/449697 of op www.wur.nl/environmental-research (ga naar 'Wageningen Environmental Research' in de grijze balk onderaan). Wageningen Environmental Research verstrekt geen gedrukte exemplaren van rapporten.

(C) 2018 Wageningen Environmental Research (instituut binnen de rechtspersoon Stichting Wageningen Research), Postbus 47, 6700 AA Wageningen, T 03174807 00, www.wur.nl/environmental-research. Wageningen Environmental Research is onderdeel van Wageningen University \& Research.

- Overname, verveelvoudiging of openbaarmaking van deze uitgave is toegestaan mits met duidelijke bronvermelding.

- Overname, verveelvoudiging of openbaarmaking is niet toegestaan voor commerciële doeleinden en/of geldelijk gewin.

- Overname, verveelvoudiging of openbaarmaking is niet toegestaan voor die gedeelten van deze uitgave waarvan duidelijk is dat de auteursrechten liggen bij derden en/of zijn voorbehouden.

Wageningen Environmental Research aanvaardt geen aansprakelijkheid voor eventuele schade voortvloeiend uit het gebruik van de resultaten van dit onderzoek of de toepassing van de adviezen.

Wageningen Environmental Research Rapport 2885 | ISSN 1566-7197

Foto omslag: De Herkules, een Amerikaanse Windmotor die zich bevindt in de Kalverpolder. De Herkules is als poldermolen geïnstalleerd in 1922 en in 1993 is hij vervangen door een elektrisch gemaal. Foto: Fabrice Ottburg(C).

Foto's in rapport: Fabrice Ottburg(C. 


\section{Inhoud}

$\begin{array}{ll}\text { Samenvatting } & 5\end{array}$

$\begin{array}{lll}1 & \text { Inleiding } & 7\end{array}$

$\begin{array}{lll}1.1 & \text { Aandachtspunten } & 7\end{array}$

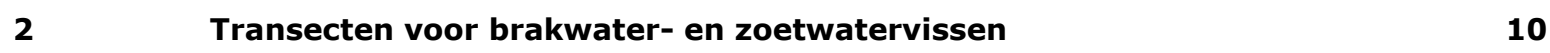

$3 \quad$ Meetpunten rugstreeppad $r$

$\begin{array}{llr}4 & \text { Transecten ringslang } & 14\end{array}$

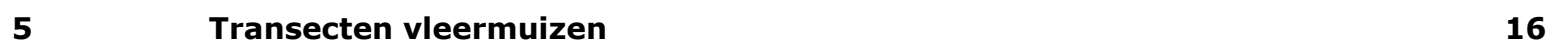

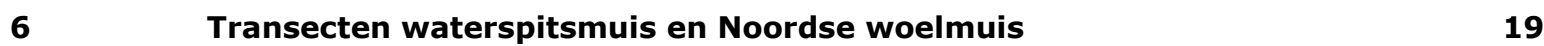

$\begin{array}{llr}7 & \text { Meetpunten bunzing en wezel } & 22\end{array}$

$8 \quad$ Transecten dagvlinders $\quad 25$

$\begin{array}{llr}9 & \text { Transecten glassnijder } & 28\end{array}$

10 Transecten moerassprinkhaan en veenmol 30

11 Transecten wilde bijen $\quad 33$

12 Transecten en meetpunten broedvogels $\quad 36$

$13 \quad$ Meetpunten planten $\quad 41$

$\begin{array}{ll}\text { Literatuur } & 47\end{array}$ 



\section{Samenvatting}

Naar aanleiding van een motie van Groen Links binnen de gemeente Zaanstad, waarin het 'Monitoren van Biodiversiteit' als speerpunt staat gemeld, heeft Wageningen Environmental Research (WENR) voor de gemeente Zaanstad onderzocht hoe biodiversiteit binnen de gemeentegrenzen kan worden gemeten en gevolgd. Deze bevindingen zijn eerder verschenen in het rapport 'Meetnet Biodiversiteit Zaanstad' (Ottburg et al. 2018).

In de voorliggende rapportage zijn op verzoek van de gemeente Zaanstad door WENR de monitoringtransecten voor de verschillende soorten, soortgroepen en habitattypen (Ottburg et al. 2018) op kaart gezet. 


\section{$1 \quad$ Inleiding}

Naar aanleiding van een motie van Groen Links binnen de gemeente Zaanstad, waarin het 'Monitoren van Biodiversiteit' als speerpunt staat gemeld, heeft Wageningen Environmental Research (WENR) voor de gemeente Zaanstad onderzocht hoe biodiversiteit binnen de gemeentegrenzen kan worden gemeten en gevolgd. Deze bevindingen zijn eerder verschenen in het rapport 'Meetnet Biodiversiteit Zaanstad' (Ottburg et al. 2018).

In de voorliggende rapportage zijn op verzoek van de gemeente Zaanstad door WENR de monitoringtransecten voor de verschillende soorten, soortgroepen en habitattypen (Ottburg et al. 2018) op kaart gezet, gerelateerd aan de 22 landschapstypen in de gemeente Zaanstad die zijn onderscheiden op basis van Veer et al. (2012) (zie ook Ottburg et al. (2018)).

De transecten die zijn neergelegd, worden gepresenteerd per soort, soortgroep en habitattypen in twee kaarten, te weten 1) transecten gelegen binnen de gemeente Zaanstad (Figuur 1 en 2) transecten gelegen in Natura 2000-gebieden die zijn gelegen binnen de begrenzing van de gemeente Zaanstad (Figuur 2).

\subsection{Aandachtspunten}

In de praktijk zal met de volgende punten rekening moeten worden gehouden:

Niet alle transecten zijn eenvoudig toegankelijk. Zo zijn transecten gelegen in de Natura 2000gebieden vaak alleen bereikbaar als men over een boot beschikt en geldt voor transecten in de schrale bermen langs de Coentunnelweg/A8 dat deze moeilijk toegankelijk zijn. Ditzelfde geldt ook voor transecten die gelegen zijn in spoorbermen en die in eigendom en beheer zijn van ProRail.

In deze situaties geldt vaak dat men toestemming van de betreffende instantie (zoals provincie NoordHolland, Rijkswaterstaat, ProRail, Staatsbosbeheer, Natuurmonumenten of gemeente Zaanstad) of particulieren nodig heeft en men vaak ook een betredingsvergunning dient aan te vragen.

De transecten en meetpunten die in de voorliggende rapportage worden weergegeven, zijn tentatief. Aanbevolen wordt dat de gemeente Zaanstad eerst de transecten voor de verschillende groepen 'bemant' en in de daarop twee volgende jaren ervaring opdoet en hier praktisch mee omgaat. Daarna kan worden geconcludeerd of een transect of meetpunt wel of niet in de uiteindelijke monitoring moet worden opgenomen. Ter illustratie: indien een transect of meetpunt in de praktijk niet kan worden gemonitord door bijvoorbeeld verandering van de habitattypen (o.a. door bebouwing) of het transect/meetpunt niet meer mag worden betreden, dient men dit pragmatisch op te lossen door een ander transect/meetpunt te kiezen.

Globaal zijn er nu voor elk landschapstype per soort/soortgroep vijf transecten of meetpunten neergelegd. Dit is niet altijd het geval, omdat er bijvoorbeeld niet altijd voldoende habitattype van het betreffende landschapstype voorhanden is, bijvoorbeeld veenheide.

Alleen voor trekvogels en wintergasten zijn geen transecten met telpunten van minimaal 5 kilometer lengte uitgelegd. Aanbevolen wordt om met de monitoring van deze vogelgroep aan te sluiten bij de monitoring van Vogelbeschermingswacht Zaanstreek (www.vogelwachtzaanstreek.nl). Er zijn wel transecten en meetpunten uitgelegd voor de andere vogelgroepen, maar naar verwachting geldt dat men ook voor deze groepen voldoende aansluiting kan vinden bij Vogelbeschermingswacht Zaanstreek. 


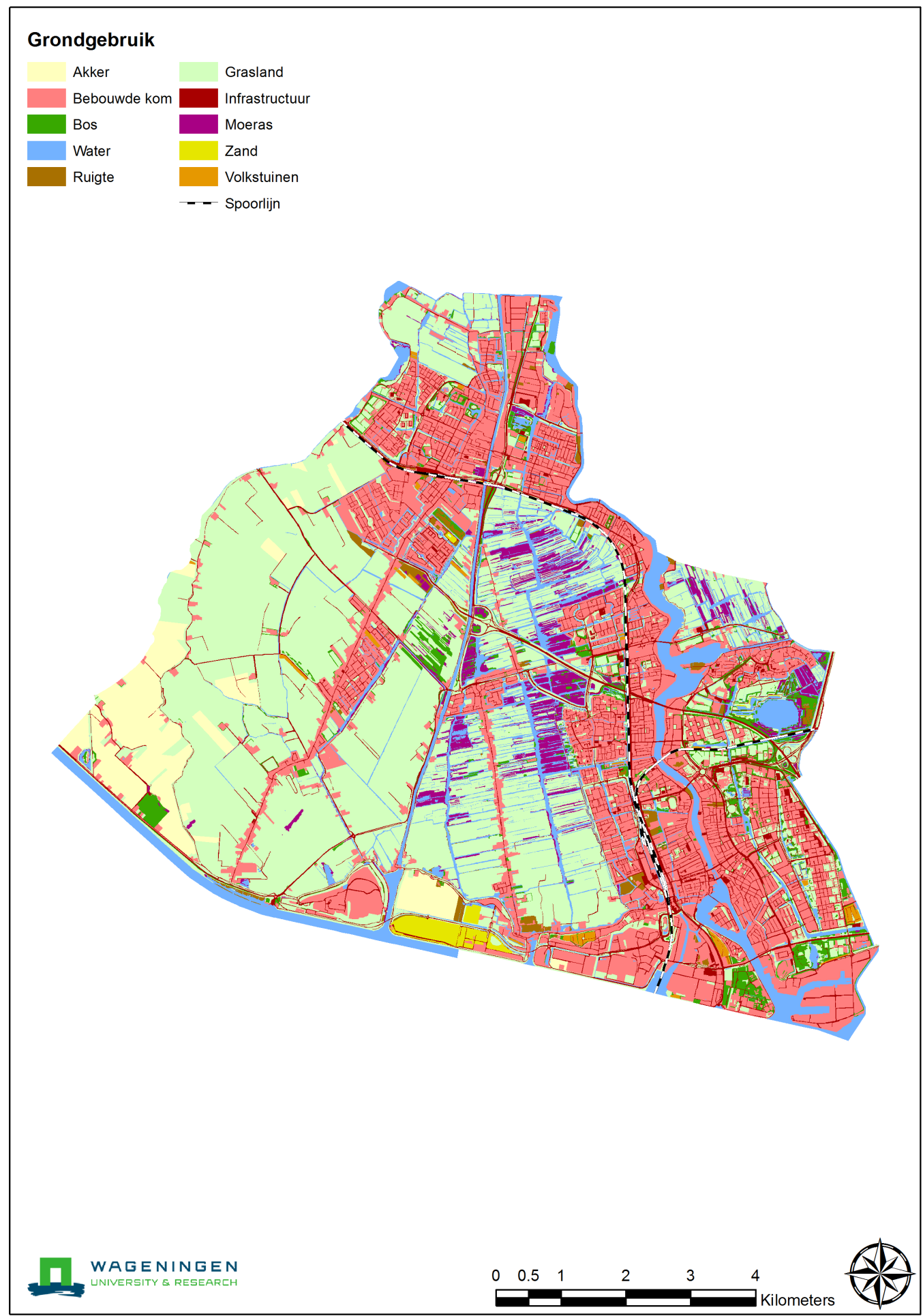

Figuur 1 Grondgebruik binnen de gemeente Zaanstad, naar voorbeeld van Veer et al. (2012). 


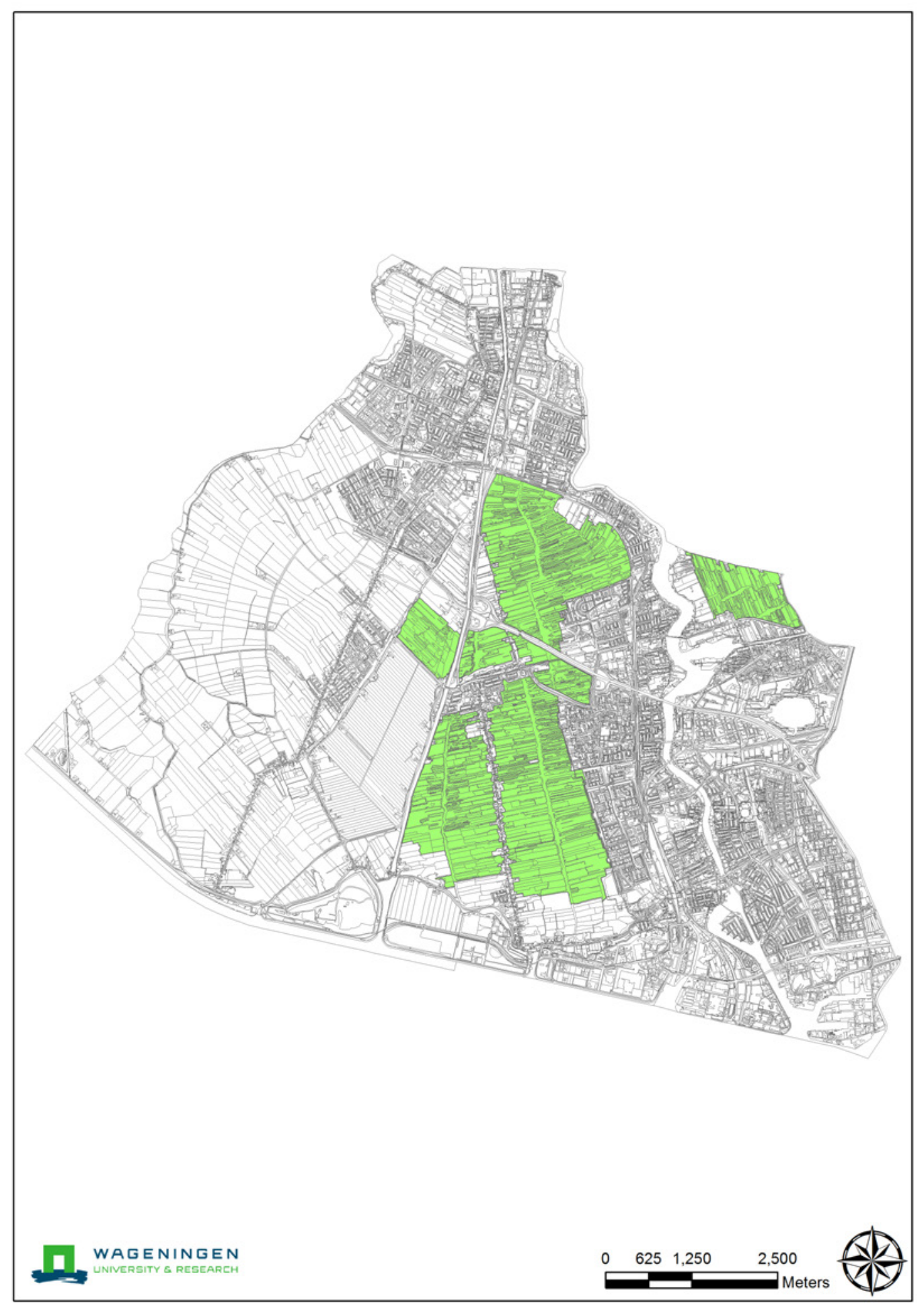

Figuur 2 Ligging Natura 2000-gebieden binnen gemeente Zaanstad. 


\section{Transecten voor brakwater- en zoetwatervissen}

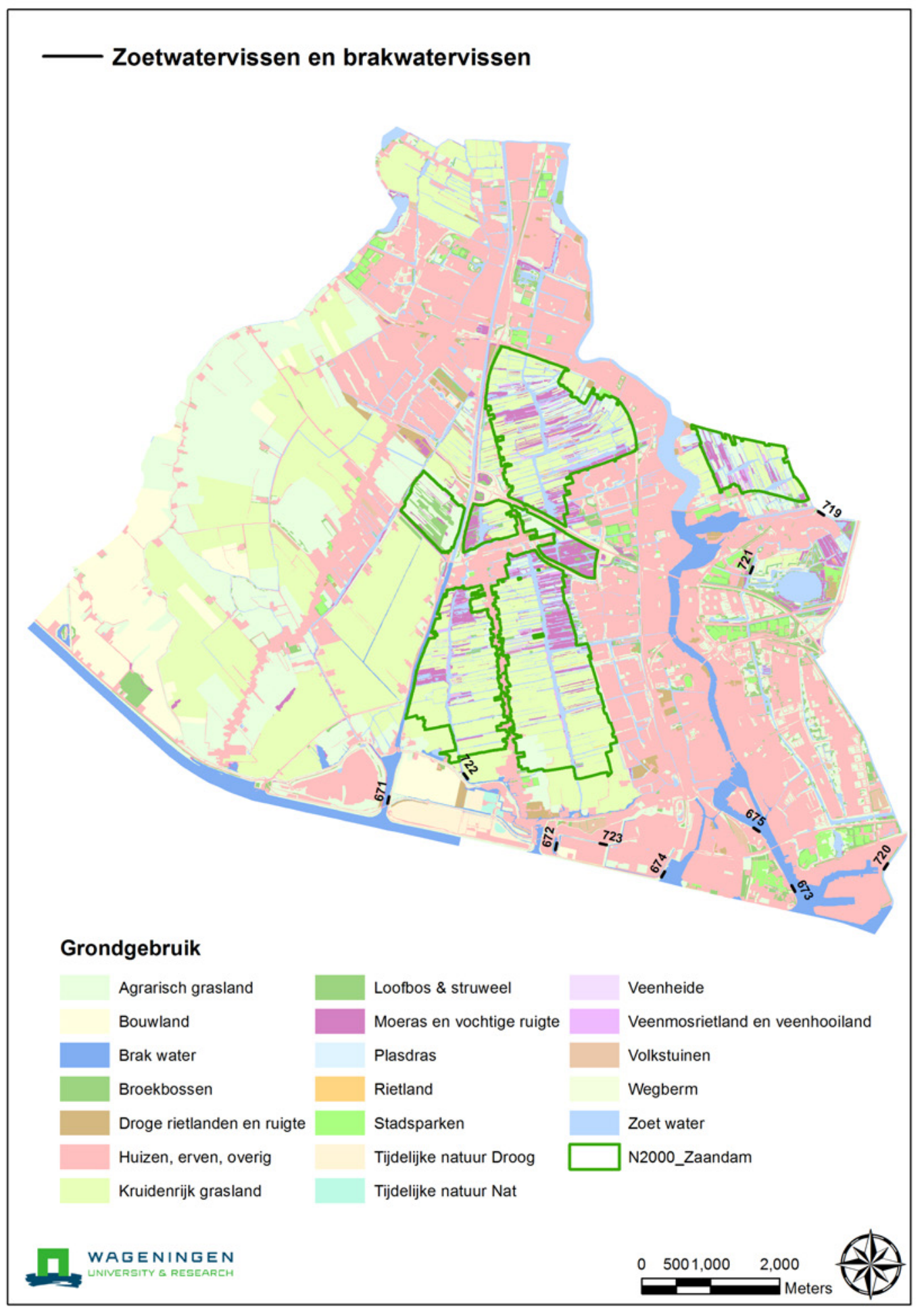

Figuur 3 Transecten voor brakwater- en zoetwatervissen. 
Tabel 1 Transecten voor brakwatervissen.

\begin{tabular}{llllllll} 
Nr. & Soort & Type & Lengte & Start X & Start Y & Eind X \\
\hline 671 & Brakwatervissen & Brakwater & 100 & 111794 & 494108 & 111817 & 494206 \\
\hline 672 & Brakwatervissen & Brakwater & 100 & 114228 & 493440 & 114249 & 493537 \\
\hline 673 & Brakwatervissen & Brakwater & 100 & 117649 & 492922 & 117697 & 492834 \\
\hline 674 & Brakwatervissen & Brakwater & 100 & 115763 & 493040 & 115813 & 493126 \\
\hline 675 & Brakwatervissen & Brakwater & 100 & 117184 & 493703 & 117100 & 493757 \\
\hline
\end{tabular}

Tabel 2 Transecten voor zoetwatervissen.

\begin{tabular}{llllllll} 
Nr. & Soort & Type & Lengte & Start X & Start Y & Eind X \\
719 & Zoetwatervissen & Zoetwater & 100 & 118035 & 498343 & 118118 & 498288 \\
\hline 720 & Zoetwatervissen & Zoetwater & 100 & 118990 & 493159 & 119046 & 493241 \\
\hline 721 & Zoetwatervissen & Zoetwater & 100 & 117048 & 497447 & 117088 & 497538 \\
\hline 722 & Zoetwatervissen & Zoetwater & 100 & 112953 & 494467 & 112893 & 494546 \\
\hline 723 & Zoetwatervissen & Zoetwater & 100 & 114873 & 493529 & 114970 & 493507 \\
\hline
\end{tabular}
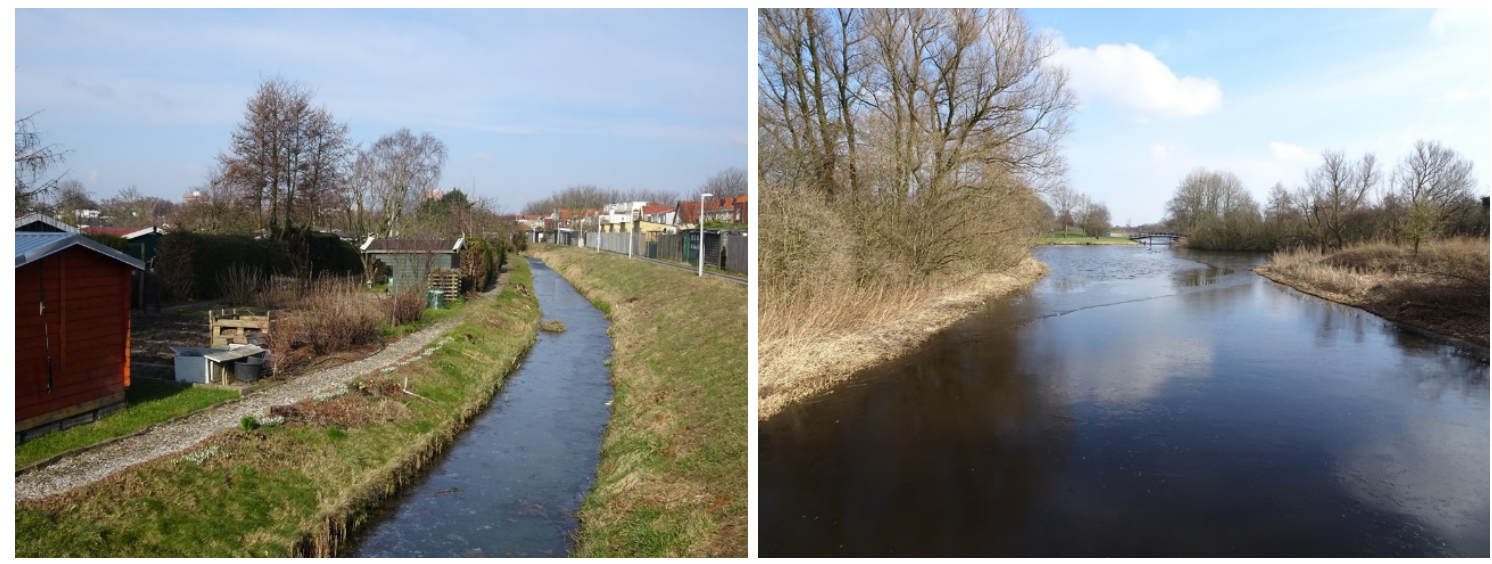

Figuur 4 Voorbeelden van transecten in landschapstype 'Zoetwater'. 


\section{$3 \quad$ Meetpunten rugstreeppad}

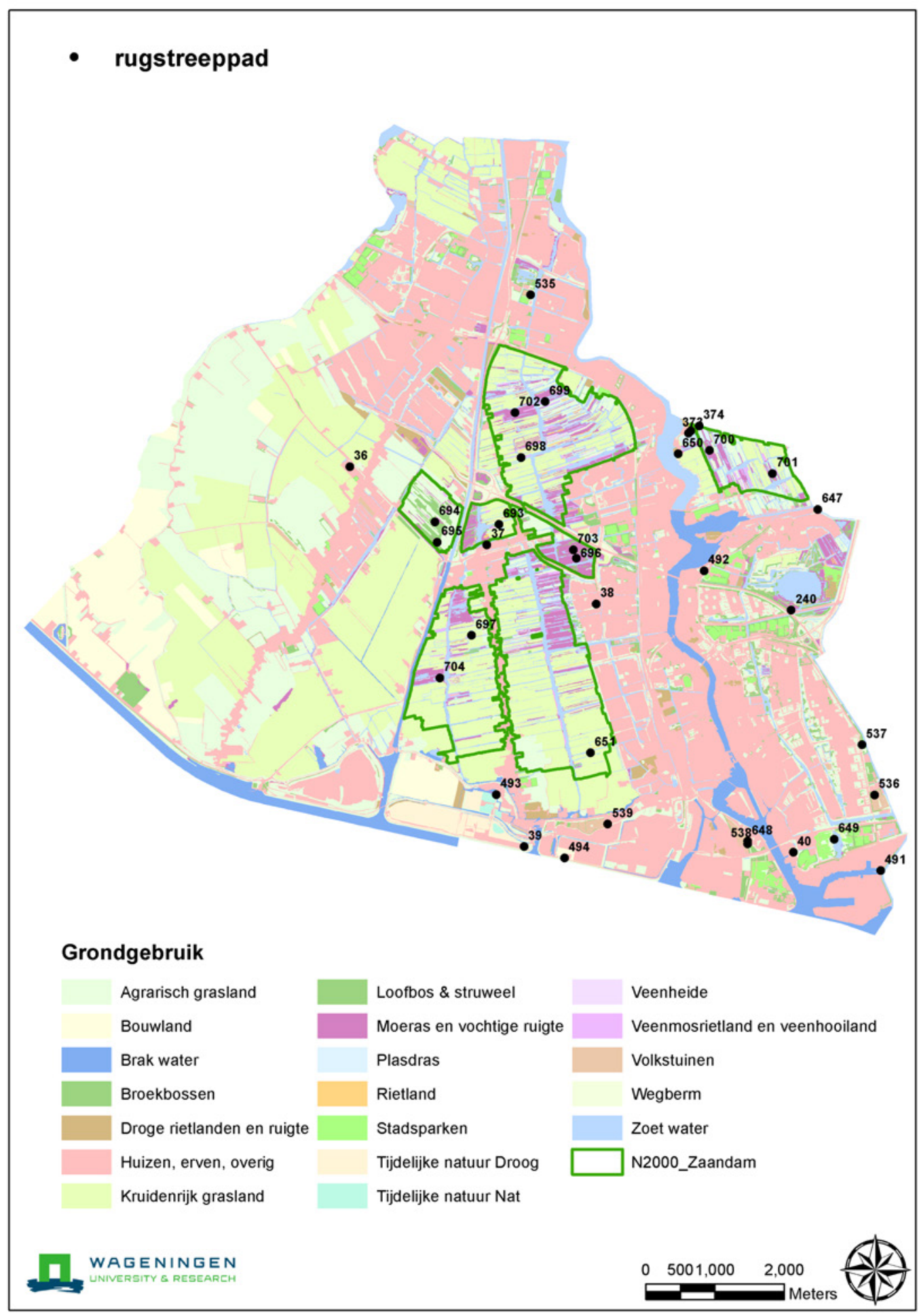

Figuur 5 Meetpunten voor de rugstreeppad. 
Tabel 3 Meetpunten voor de rugstreeppad.

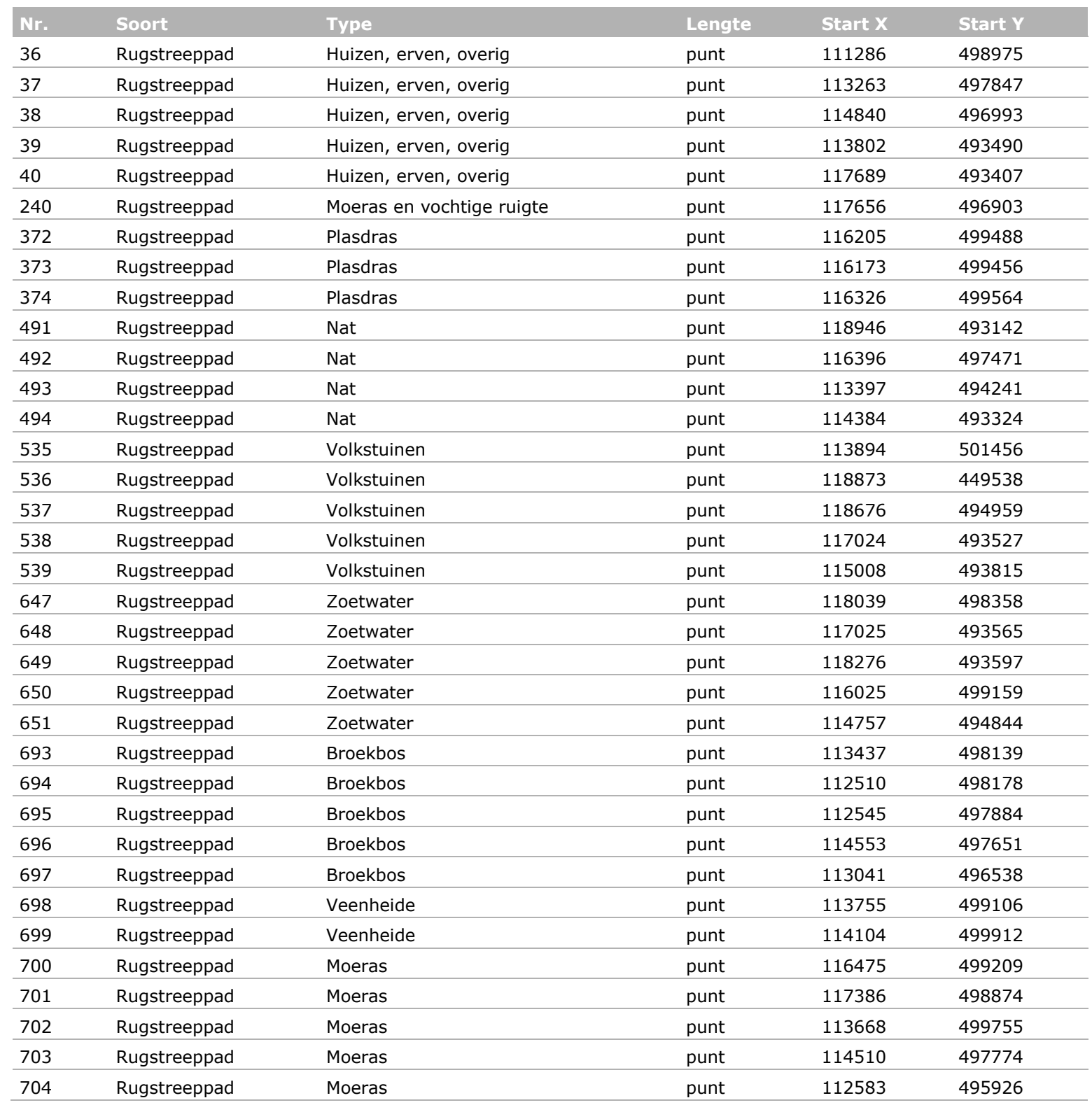
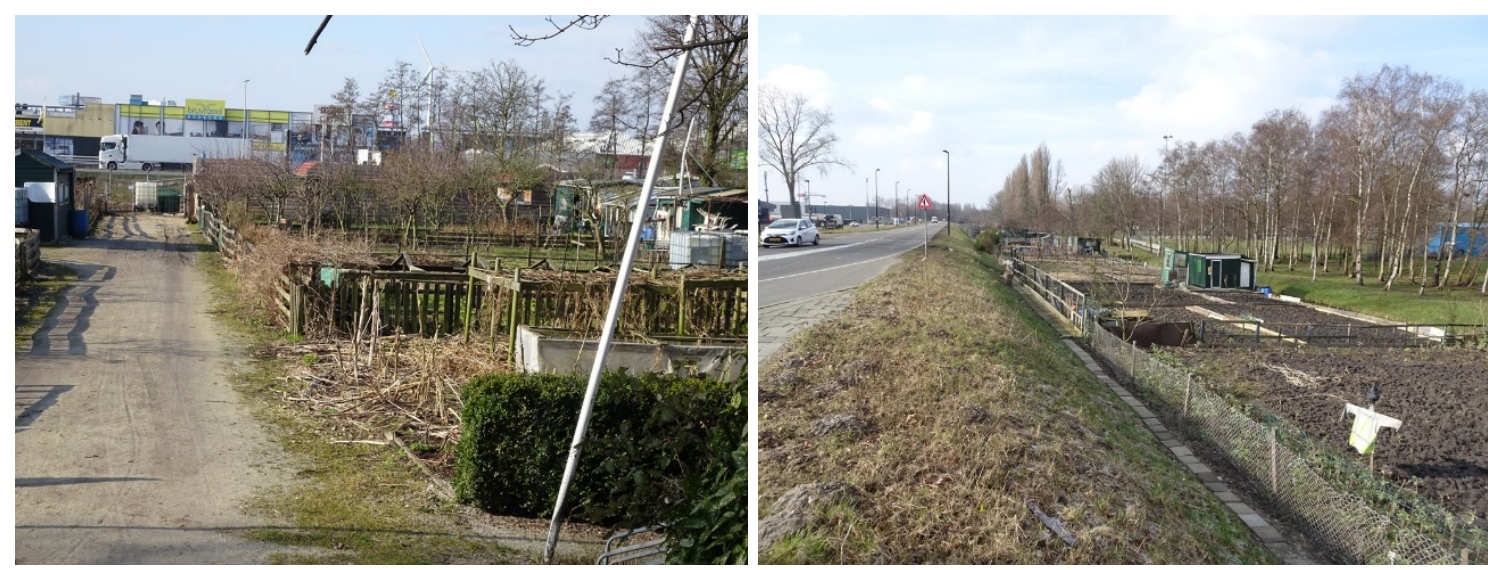

Figuur 6 Voorbeelden meetpunten in landschapstype 'Volkstuinen'. 


\section{$4 \quad$ Transecten ringslang}

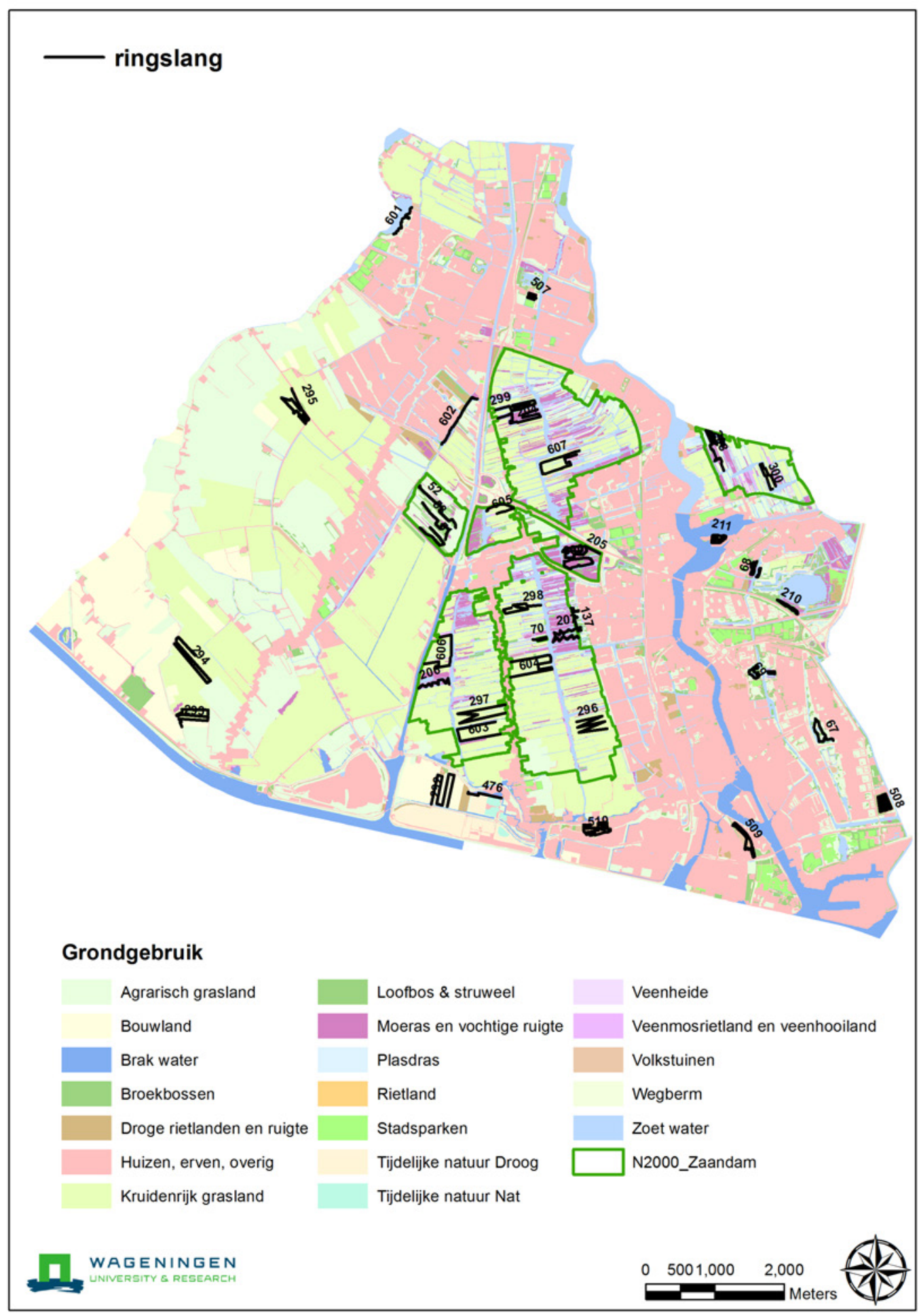

Figuur 7 Transecten voor de ringslang. 
Tabel 4 Transecten voor de ringslang.

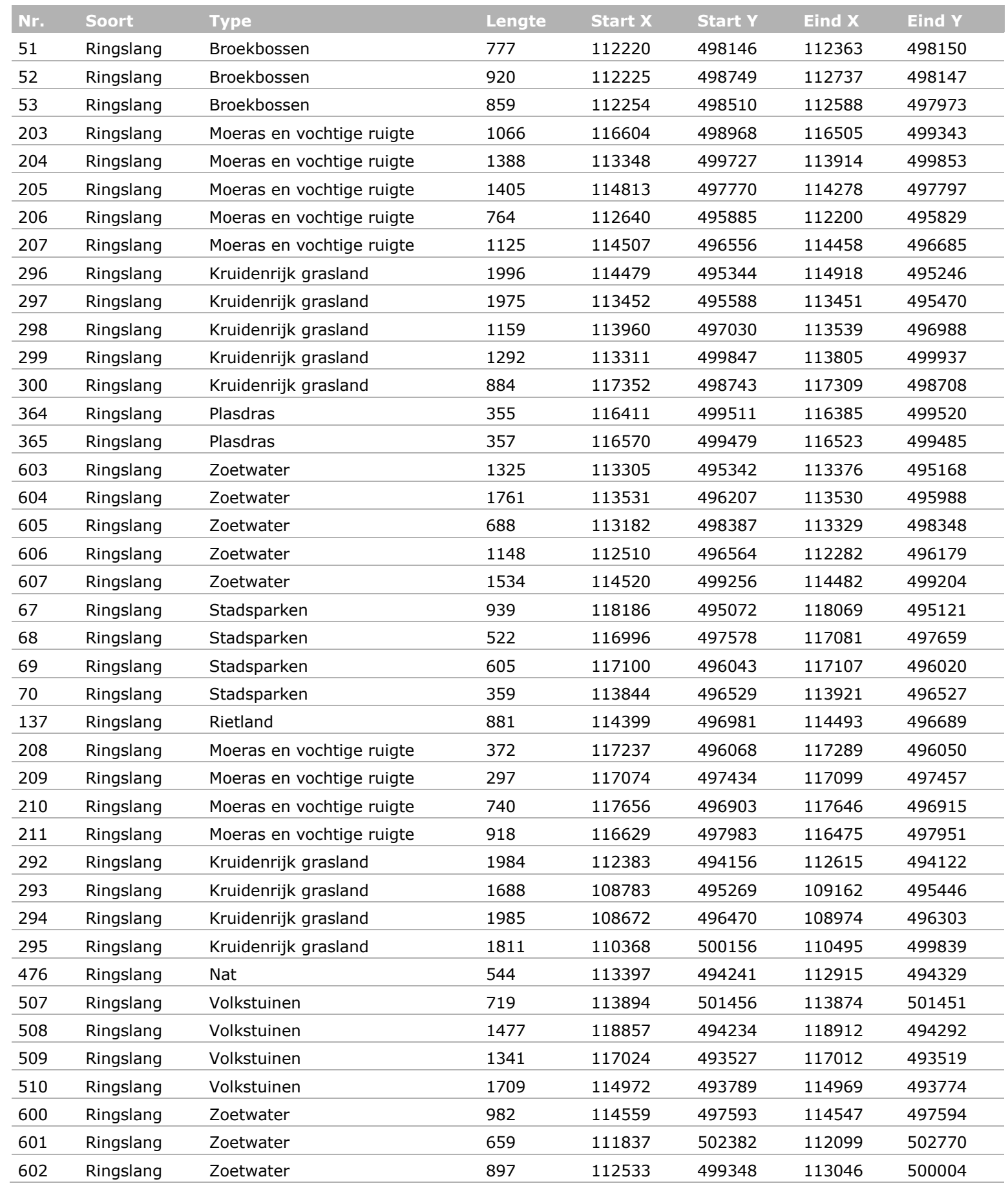




\section{Transecten vleermuizen}

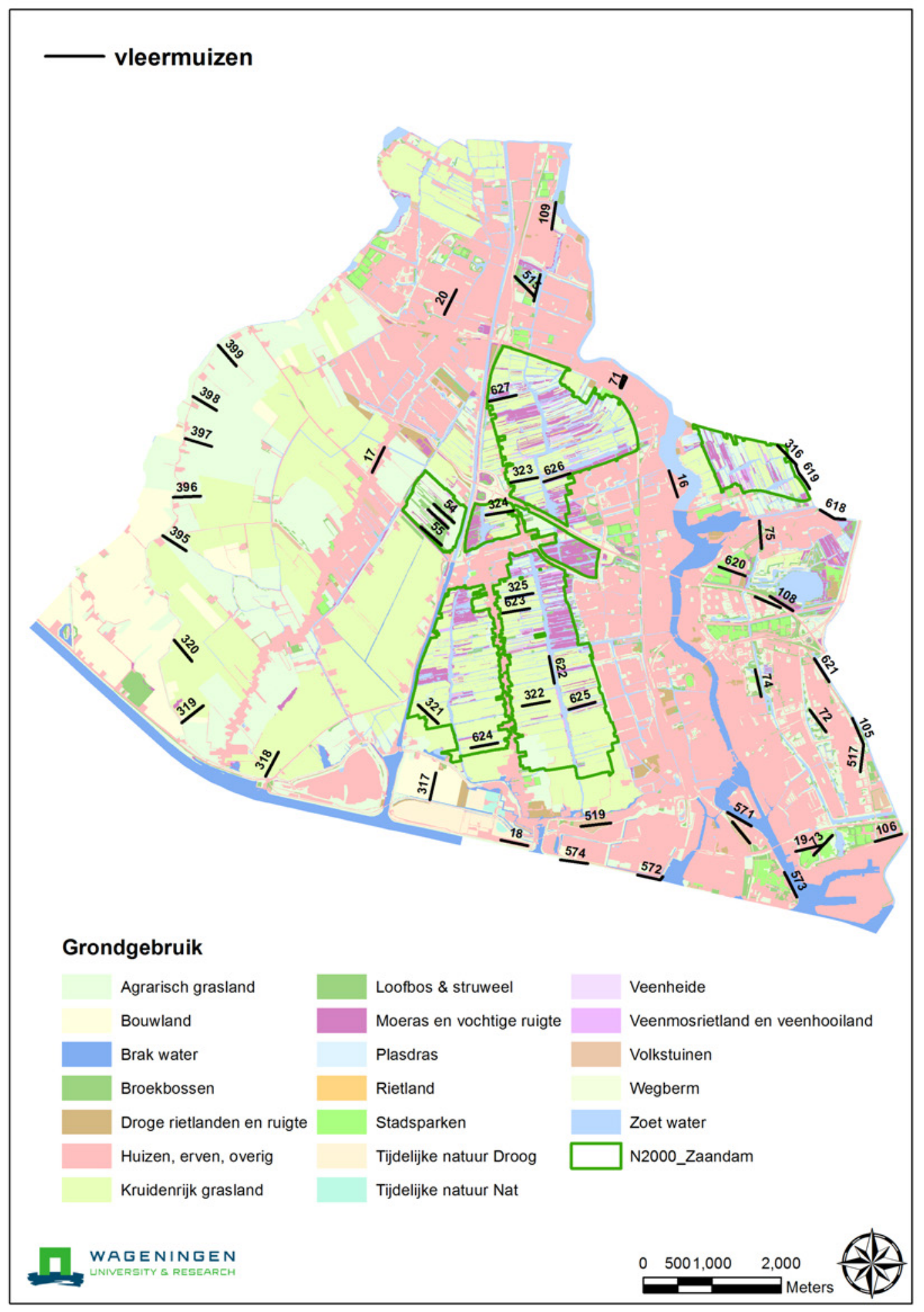

Figuur 8 Transecten voor vleermuizen. 
Tabel 5 Transecten voor vleermuizen.

\begin{tabular}{|c|c|c|c|c|c|c|c|}
\hline Nr. & Soort & Type & Lengte & Start X & Start Y & Eind $\mathrm{X}$ & Eind $Y$ \\
\hline 54 & Vleermuizen & Broekbossen & 400 & 112436 & 498440 & 112735 & 498174 \\
\hline 55 & Vleermuizen & Broekbossen & 400 & 112251 & 498110 & 112554 & 497848 \\
\hline 321 & Vleermuizen & Kruidenrijk grasland & 400 & 112210 & 495532 & 112504 & 495261 \\
\hline 322 & Vleermuizen & Kruidenrijk grasland & 400 & 113720 & 495516 & 114114 & 495586 \\
\hline 324 & Vleermuizen & Kruidenrijk grasland & 400 & 113198 & 498280 & 113591 & 498351 \\
\hline 325 & Vleermuizen & Kruidenrijk grasland & 400 & 113484 & 497078 & 113878 & 497149 \\
\hline 623 & Vleermuizen & Zoetwater & 400 & 113439 & 496859 & 113832 & 496930 \\
\hline 624 & Vleermuizen & Zoetwater & 400 & 112975 & 494907 & 113368 & 494978 \\
\hline 16 & Vleermuizen & Huizen, erven, overig & 400 & 115978 & 498548 & 115853 & 498928 \\
\hline 17 & Vleermuizen & Huizen, erven, overig & 400 & 111545 & 498906 & 111719 & 499266 \\
\hline 18 & Vleermuizen & Huizen, erven, overig & 400 & 113802 & 493490 & 113411 & 493572 \\
\hline 19 & Vleermuizen & Huizen, erven, overig & 400 & 117689 & 493407 & 118078 & 493500 \\
\hline 20 & Vleermuizen & Huizen, erven, overig & 400 & 112594 & 501192 & 112766 & 501553 \\
\hline 71 & Vleermuizen & Stadsparken & 400 & 115139 & 500160 & 115142 & 500133 \\
\hline 72 & Vleermuizen & Stadsparken & 400 & 118132 & 495141 & 117891 & 495460 \\
\hline 73 & Vleermuizen & Stadsparken & 400 & 117949 & 493352 & 118225 & 493641 \\
\hline 74 & Vleermuizen & Stadsparken & 400 & 117100 & 496043 & 117187 & 495653 \\
\hline 109 & Vleermuizen & Loofbos \& struweel & 400 & 114211 & 502821 & 114147 & 502426 \\
\hline 316 & Vleermuizen & Kruidenrijk grasland & 400 & 117702 & 499007 & 117423 & 499293 \\
\hline 317 & Vleermuizen & Kruidenrijk grasland & 400 & 112383 & 494156 & 112470 & 494546 \\
\hline 318 & Vleermuizen & Kruidenrijk grasland & 400 & 109996 & 494494 & 110188 & 494845 \\
\hline 319 & Vleermuizen & Kruidenrijk grasland & 400 & 108783 & 495269 & 109097 & 495517 \\
\hline 320 & Vleermuizen & Kruidenrijk grasland & 400 & 108672 & 496470 & 108929 & 496163 \\
\hline 395 & Vleermuizen & Agrarisch grasland & 404 & 108508 & 497985 & 108848 & 497767 \\
\hline 396 & Vleermuizen & Agrarisch grasland & 400 & 108660 & 498542 & 109060 & 498557 \\
\hline 397 & Vleermuizen & Agrarisch grasland & 400 & 108833 & 499395 & 109216 & 499281 \\
\hline 398 & Vleermuizen & Agrarisch grasland & 400 & 108946 & 500005 & 109290 & 499801 \\
\hline 399 & Vleermuizen & Agrarisch grasland & 400 & 109310 & 500746 & 109577 & 500448 \\
\hline 515 & Vleermuizen & Volkstuinen & 400 & 113894 & 501456 & 113618 & 501745 \\
\hline 517 & Vleermuizen & Volkstuinen & 400 & 118676 & 494959 & 118624 & 494562 \\
\hline 518 & Vleermuizen & Volkstuinen & 400 & 117024 & 493527 & 116770 & 493836 \\
\hline 519 & Vleermuizen & Volkstuinen & 438 & 115008 & 493815 & 114573 & 493766 \\
\hline 570 & Vleermuizen & Brakwater & 400 & 113890 & 501386 & 113984 & 501775 \\
\hline 571 & Vleermuizen & Brakwater & 400 & 116697 & 493971 & 117046 & 493775 \\
\hline
\end{tabular}




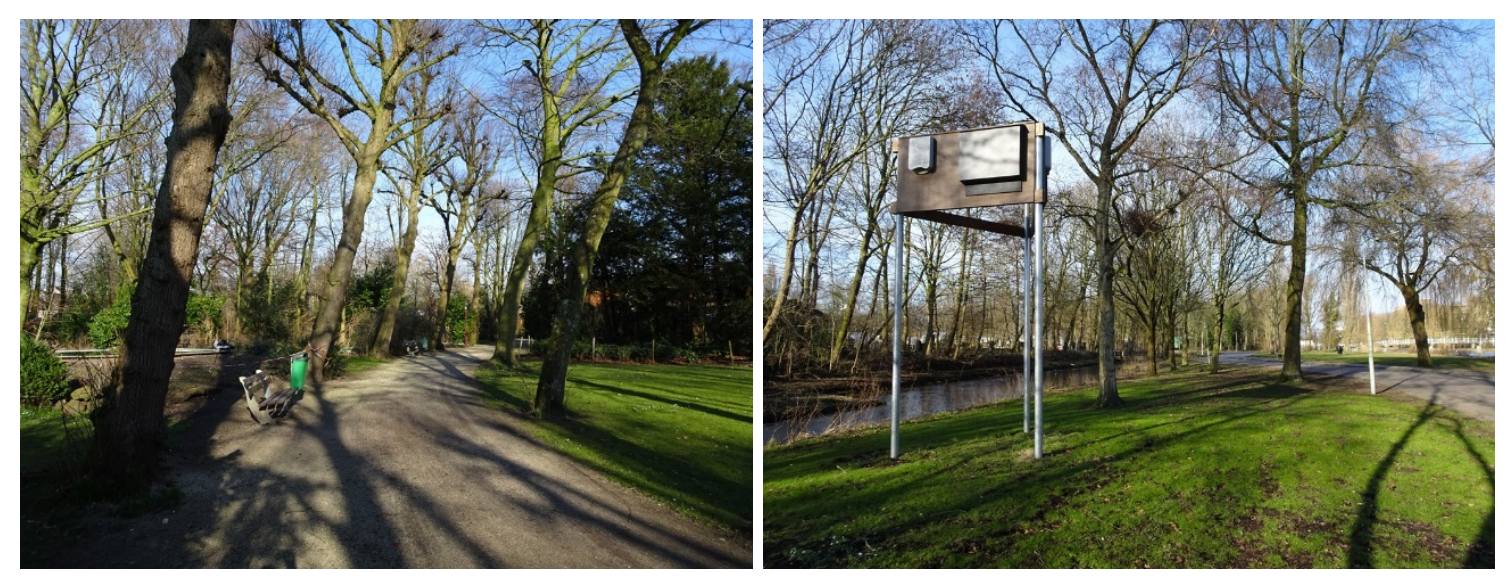

Figuur 9 Voorbeelden transecten in landschapstype 'Stadsparken'. 


\section{Transecten waterspitsmuis en Noordse woelmuis}

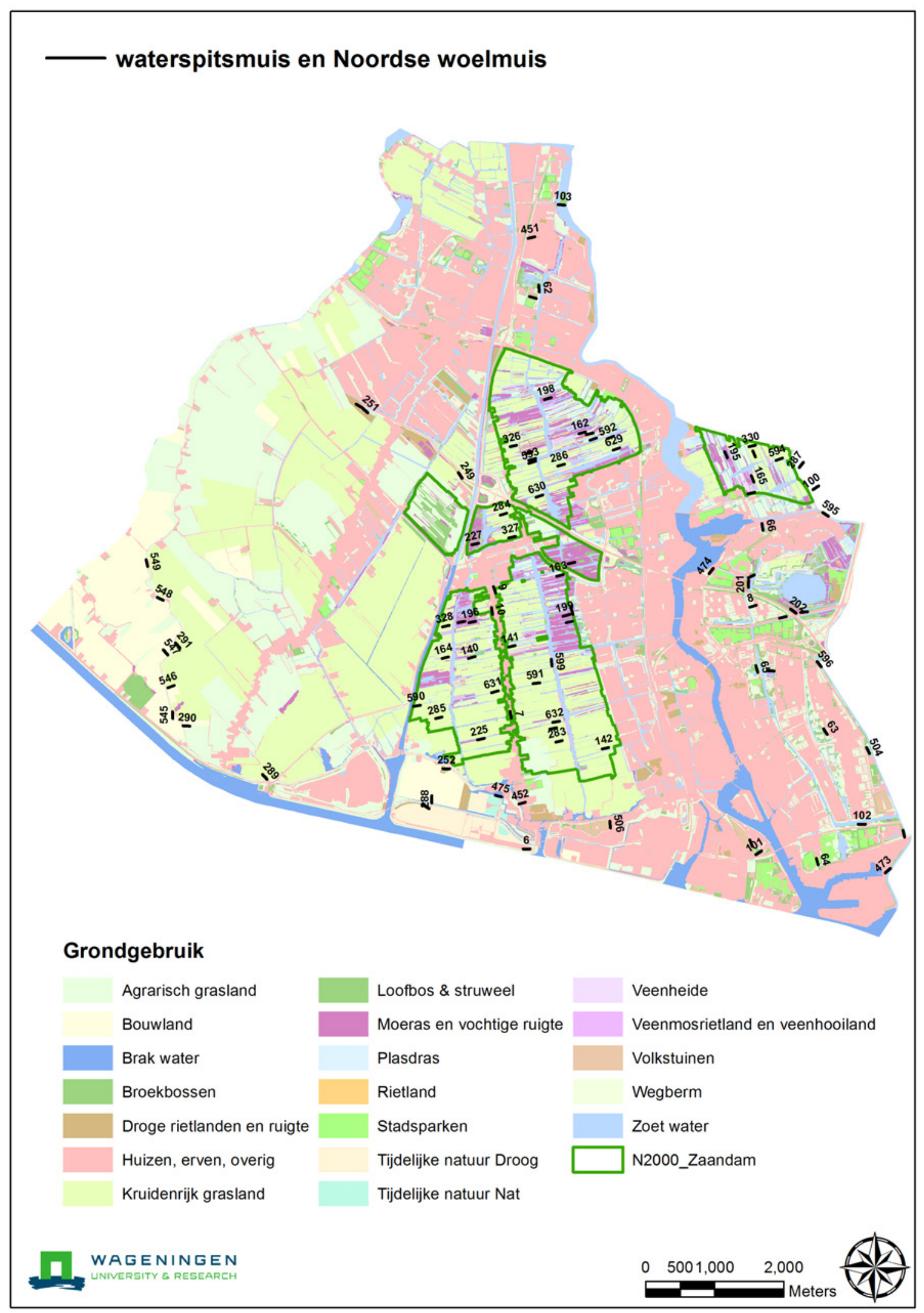

Figuur 10 Transecten waterspitsmuis en Noordse woelmuis. 
Tabel 6 Transecten voor waterspitsmuis en Noordse woelmuis.

\begin{tabular}{|c|c|c|c|c|c|c|c|}
\hline Nr. & Soort & Tyре & Lengte & Start X & Start Y & Eind $X$ & Eind $\mathrm{Y}$ \\
\hline 161 & Noordse woelmuis & Veenmosrietland & 100 & 113787 & 499114 & 113884 & 499139 \\
\hline 162 & Noordse woelmuis & Veenmosrietland & 100 & 114512 & 499500 & 114609 & 499524 \\
\hline 163 & Noordse woelmuis & Veenmosrietland & 100 & 114189 & 497437 & 114286 & 497462 \\
\hline 164 & Noordse woelmuis & Veenmosrietland & 100 & 112529 & 496243 & 112626 & 496267 \\
\hline 165 & Noordse woelmuis & Veenmosrietland & 100 & 117044 & 498800 & 117007 & 498893 \\
\hline 195 & Noordse woelmuis & Moeras en vochtige ruigte & 100 & 116659 & 499150 & 116621 & 499243 \\
\hline 196 & Noordse woelmuis & Moeras en vochtige ruigte & 100 & 112921 & 496761 & 113018 & 496785 \\
\hline 197 & Noordse woelmuis & Moeras en vochtige ruigte & 100 & 114355 & 497616 & 114452 & 497641 \\
\hline 198 & Noordse woelmuis & Moeras en vochtige ruigte & 100 & 114012 & 499995 & 114109 & 500019 \\
\hline 199 & Noordse woelmuis & Moeras en vochtige ruigte & 100 & 114283 & 496857 & 114380 & 496882 \\
\hline 282 & Noordse woelmuis & Kruidenrijk grasland & 100 & 117068 & 499161 & 117030 & 499254 \\
\hline 283 & Noordse woelmuis & Kruidenrijk grasland & 100 & 114174 & 495034 & 114271 & 495059 \\
\hline 284 & Noordse woelmuis & Kruidenrijk grasland & 100 & 113371 & 498323 & 113468 & 498347 \\
\hline 285 & Noordse woelmuis & Kruidenrijk grasland & 100 & 112436 & 495374 & 112533 & 495398 \\
\hline 286 & Noordse woelmuis & Kruidenrijk grasland & 100 & 114205 & 499032 & 114302 & 499057 \\
\hline 590 & Noordse woelmuis & Zoetwater & 100 & 112117 & 495554 & 112216 & 495569 \\
\hline 591 & Noordse woelmuis & Zoetwater & 100 & 113848 & 495880 & 113947 & 495894 \\
\hline 592 & Noordse woelmuis & Zoetwater & 100 & 114922 & 499428 & 115015 & 499465 \\
\hline 593 & Noordse woelmuis & Zoetwater & 100 & 113787 & 499070 & 113882 & 499100 \\
\hline 594 & Noordse woelmuis & Zoetwater & 100 & 117364 & 499116 & 117459 & 499146 \\
\hline 6 & Noordse woelmuis en Waterspitsmuis & Huizen, erven, overig & 100 & 113802 & 493490 & 113702 & 493489 \\
\hline 7 & Noordse woelmuis en Waterspitsmuis & Huizen, erven, overig & 100 & 113530 & 495381 & 113518 & 495480 \\
\hline 8 & Noordse woelmuis en Waterspitsmuis & Huizen, erven, overig & 100 & 116984 & 496988 & 117080 & 497018 \\
\hline 9 & Noordse woelmuis en Waterspitsmuis & Huizen, erven, overig & 100 & 113276 & 497288 & 113304 & 497192 \\
\hline 10 & Noordse woelmuis en Waterspitsmuis & Huizen, erven, overig & 100 & 113265 & 496884 & 113244 & 496982 \\
\hline 62 & Noordse woelmuis en Waterspitsmuis & Stadsparken & 100 & 113931 & 501653 & 113942 & 501554 \\
\hline 63 & Noordse woelmuis en Waterspitsmuis & Stadsparken & 100 & 118054 & 495227 & 118108 & 495143 \\
\hline 64 & Noordse woelmuis en Waterspitsmuis & Stadsparken & 100 & 117949 & 493352 & 117974 & 493255 \\
\hline 65 & Noordse woelmuis en Waterspitsmuis & Stadsparken & 100 & 117100 & 496043 & 117075 & 496140 \\
\hline 66 & Noordse woelmuis en Waterspitsmuis & Stadsparken & 100 & 117160 & 498198 & 117177 & 498099 \\
\hline 100 & Noordse woelmuis en Waterspitsmuis & Loofbos \& struweel & 100 & 117899 & 498687 & 117981 & 498744 \\
\hline 101 & Noordse woelmuis en Waterspitsmuis & Loofbos \& struweel & 100 & 117157 & 493459 & 117072 & 493407 \\
\hline 102 & Noordse woelmuis en Waterspitsmuis & Loofbos \& struweel & 100 & 118656 & 493844 & 118556 & 493844 \\
\hline 103 & Noordse woelmuis en Waterspitsmuis & Loofbos \& struweel & 100 & 114211 & 502821 & 114310 & 502809 \\
\hline 104 & Noordse woelmuis en Waterspitsmuis & Loofbos \& struweel & 100 & 119227 & 493657 & 119206 & 493755 \\
\hline 136 & Noordse woelmuis en Waterspitsmuis & Rietland & 100 & 114399 & 496981 & 114426 & 496885 \\
\hline 200 & Noordse woelmuis en Waterspitsmuis & Moeras en vochtige ruigte & 100 & 117237 & 496068 & 117337 & 496063 \\
\hline 201 & Noordse woelmuis en Waterspitsmuis & Moeras en vochtige ruigte & 100 & 116966 & 497373 & 116968 & 497273 \\
\hline 202 & Noordse woelmuis en Waterspitsmuis & Moeras en vochtige ruigte & 100 & 117656 & 496903 & 117573 & 496959 \\
\hline 248 & Noordse woelmuis en Waterspitsmuis & Droge rietlanden en ruigte & 100 & 116961 & 497410 & 117049 & 497457 \\
\hline 249 & Noordse woelmuis en Waterspitsmuis & Droge rietlanden en ruigte & 100 & 112769 & 498940 & 112822 & 498855 \\
\hline 250 & Noordse woelmuis en Waterspitsmuis & Droge rietlanden en ruigte & 100 & 111371 & 499877 & 111286 & 499930 \\
\hline 251 & Noordse woelmuis en Waterspitsmuis & Droge rietlanden en ruigte & 114 & 111371 & 499877 & 111457 & 499802 \\
\hline 252 & Noordse woelmuis en Waterspitsmuis & Droge rietlanden en ruigte & 100 & 112541 & 494651 & 112641 & 494652 \\
\hline 287 & Noordse woelmuis en Waterspitsmuis & Kruidenrijk grasland & 100 & 117702 & 499007 & 117761 & 499087 \\
\hline 288 & Noordse woelmuis en Waterspitsmuis & Kruidenrijk grasland & 100 & 112383 & 494156 & 112383 & 494256 \\
\hline 289 & Noordse woelmuis en Waterspitsmuis & Kruidenrijk grasland & 100 & 109996 & 494494 & 109930 & 494569 \\
\hline 290 & Noordse woelmuis en Waterspitsmuis & Kruidenrijk grasland & 100 & 108783 & 495269 & 108883 & 495263 \\
\hline 291 & Noordse woelmuis en Waterspitsmuis & Kruidenrijk grasland & 100 & 108672 & 496470 & 108737 & 496394 \\
\hline 450 & Noordse woelmuis en Waterspitsmuis & Droog & 100 & 112342 & 494073 & 112256 & 494124 \\
\hline 451 & Noordse woelmuis en Waterspitsmuis & Droog & 100 & 113775 & 502331 & 113874 & 502348 \\
\hline 452 & Noordse woelmuis en Waterspitsmuis & Droog & 100 & 113739 & 494163 & 113642 & 494138 \\
\hline 473 & Noordse woelmuis en Waterspitsmuis & Nat & 100 & 118946 & 493142 & 119022 & 493207 \\
\hline 474 & Noordse woelmuis en Waterspitsmuis & Nat & 100 & 116396 & 497471 & 116454 & 497553 \\
\hline 475 & Noordse woelmuis en Waterspitsmuis & Nat & 100 & 113397 & 494241 & 113300 & 494263 \\
\hline 503 & Noordse woelmuis en Waterspitsmuis & Volkstuinen & 100 & 113894 & 501456 & 113799 & 501487 \\
\hline 504 & Noordse woelmuis en Waterspitsmuis & Volkstuinen & 100 & 118676 & 494959 & 118716 & 494867 \\
\hline
\end{tabular}




\begin{tabular}{|c|c|c|c|c|c|c|c|}
\hline Nr. & Soort & Type & Lengte & Start X & Start Y & Eind $X$ & Eind $Y$ \\
\hline 505 & Noordse woelmuis en Waterspitsmuis & Volkstuinen & 100 & 117024 & 493527 & 116985 & 493619 \\
\hline 506 & Noordse woelmuis en Waterspitsmuis & Volkstuinen & 100 & 114972 & 493789 & 114956 & 493888 \\
\hline 545 & Noordse woelmuis en Waterspitsmuis & Bouwland & 100 & 108630 & 495476 & 108632 & 495376 \\
\hline 546 & Noordse woelmuis en Waterspitsmuis & Bouwland & 100 & 108563 & 495820 & 108656 & 495856 \\
\hline 547 & Noordse woelmuis en Waterspitsmuis & Bouwland & 100 & 108561 & 496295 & 108496 & 496371 \\
\hline 548 & Noordse woelmuis en Waterspitsmuis & Bouwland & 100 & 108497 & 497086 & 108407 & 497130 \\
\hline 549 & Noordse woelmuis en Waterspitsmuis & Bouwland & 100 & 108269 & 497579 & 108250 & 497677 \\
\hline 595 & Noordse woelmuis en Waterspitsmuis & Zoetwater & 100 & 118039 & 498358 & 118122 & 498302 \\
\hline 596 & Noordse woelmuis en Waterspitsmuis & Zoetwater & 100 & 117956 & 496200 & 118020 & 496123 \\
\hline 597 & Noordse woelmuis en Waterspitsmuis & Zoetwater & 100 & 117412 & 496829 & 117510 & 496848 \\
\hline 598 & Noordse woelmuis en Waterspitsmuis & Zoetwater & 100 & 117724 & 496913 & 117824 & 496920 \\
\hline 599 & Noordse woelmuis en Waterspitsmuis & Zoetwater & 100 & 114110 & 496237 & 114121 & 496138 \\
\hline 138 & Waterspitsmuis & Rietland & 100 & 114670 & 499406 & 114765 & 499439 \\
\hline 139 & Waterspitsmuis & Rietland & 100 & 113740 & 499206 & 113835 & 499239 \\
\hline 140 & Waterspitsmuis & Rietland & 100 & 112911 & 496247 & 113008 & 496273 \\
\hline 141 & Waterspitsmuis & Rietland & 100 & 113492 & 496413 & 113589 & 496435 \\
\hline 142 & Waterspitsmuis & Rietland & 100 & 114846 & 494937 & 114944 & 494960 \\
\hline 224 & Waterspitsmuis & Moeras en vochtige ruigte & 100 & 114323 & 496765 & 114420 & 496788 \\
\hline 225 & Waterspitsmuis & Moeras en vochtige ruigte & 100 & 113045 & 495066 & 113142 & 495088 \\
\hline 226 & Waterspitsmuis & Moeras en vochtige ruigte & 100 & 112763 & 496761 & 112861 & 496783 \\
\hline 227 & Waterspitsmuis & Moeras en vochtige ruigte & 100 & 112963 & 497890 & 113060 & 497912 \\
\hline 228 & Waterspitsmuis & Moeras en vochtige ruigte & 100 & 114617 & 499489 & 114714 & 499511 \\
\hline 326 & Waterspitsmuis & Kruidenrijk grasland & 100 & 113514 & 499312 & 113611 & 499334 \\
\hline 327 & Waterspitsmuis & Kruidenrijk grasland & 100 & 113494 & 497989 & 113591 & 498011 \\
\hline 328 & Waterspitsmuis & Kruidenrijk grasland & 100 & 112539 & 496703 & 112636 & 496725 \\
\hline 329 & Waterspitsmuis & Kruidenrijk grasland & 100 & 114091 & 495223 & 114188 & 495245 \\
\hline 330 & Waterspitsmuis & Kruidenrijk grasland & 100 & 116972 & 499311 & 117069 & 499333 \\
\hline 628 & Waterspitsmuis & Zoetwater & 100 & 116956 & 498627 & 117054 & 498649 \\
\hline 629 & Waterspitsmuis & Zoetwater & 100 & 115006 & 499263 & 115101 & 499294 \\
\hline 630 & Waterspitsmuis & Zoetwater & 100 & 113893 & 498582 & 113988 & 498613 \\
\hline 631 & Waterspitsmuis & Zoetwater & 100 & 113247 & 495752 & 113343 & 495779 \\
\hline 632 & Waterspitsmuis & Zoetwater & 100 & 114135 & 495319 & 114233 & 495338 \\
\hline
\end{tabular}
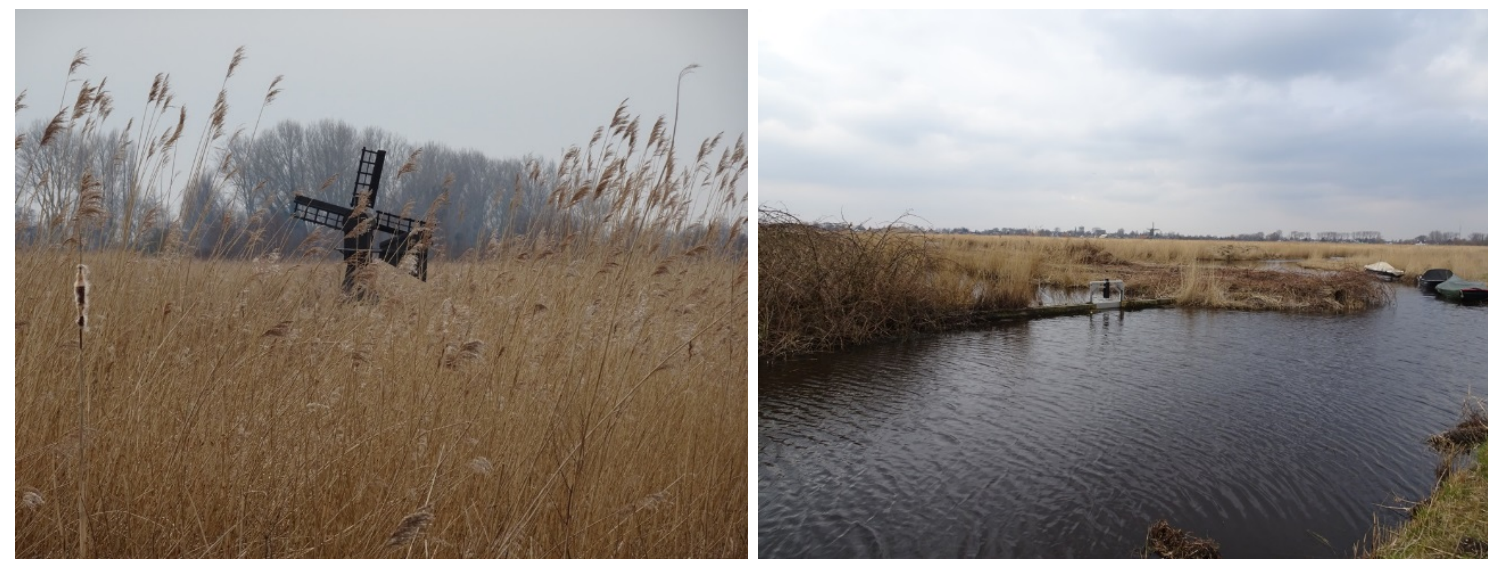

Figuur 11 Voorbeelden transecten in landschapstype 'Rietland'. 


\section{$7 \quad$ Meetpunten bunzing en wezel}

\section{- bunzing en wezel}

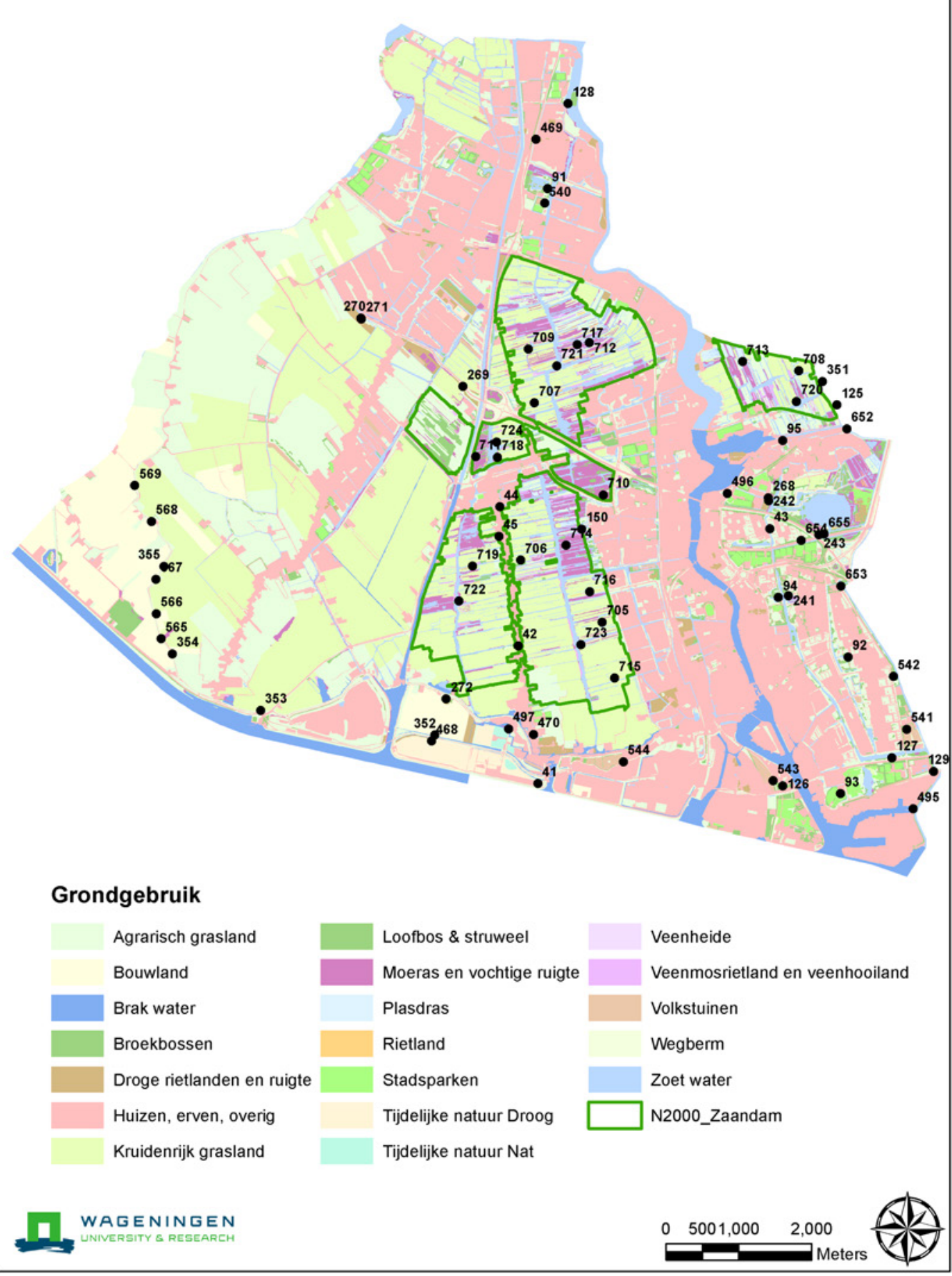

Figuur 12 Meetpunten voor bunzing en wezel. 
Tabel 7 Meetpunten voor bunzing en wezel.

\begin{tabular}{|c|c|c|c|c|c|}
\hline Nr. & Soort & Type & Lengte & Start X & Start Y \\
\hline 41 & Bunzing en wezel & Huizen, erven, overig & punt & 113802 & 493490 \\
\hline 42 & Bunzing en wezel & Huizen, erven, overig & punt & 113530 & 495381 \\
\hline 43 & Bunzing en wezel & Huizen, erven, overig & punt & 116984 & 496988 \\
\hline 44 & Bunzing en wezel & Huizen, erven, overig & punt & 113276 & 497288 \\
\hline 45 & Bunzing en wezel & Huizen, erven, overig & punt & 113265 & 496884 \\
\hline 91 & Bunzing en wezel & Stadsparken & punt & 113931 & 501653 \\
\hline 92 & Bunzing en wezel & Stadsparken & punt & 118054 & 495227 \\
\hline 93 & Bunzing en wezel & Stadsparken & punt & 117949 & 493352 \\
\hline 94 & Bunzing en wezel & Stadsparken & punt & 117100 & 496043 \\
\hline 95 & Bunzing en wezel & Stadsparken & punt & 117160 & 498198 \\
\hline 125 & Bunzing en wezel & Loofbos \& struweel & punt & 117899 & 498687 \\
\hline 126 & Bunzing en wezel & Loofbos \& struweel & punt & 117157 & 493459 \\
\hline 127 & Bunzing en wezel & Loofbos \& struweel & punt & 118656 & 493844 \\
\hline 128 & Bunzing en wezel & Loofbos \& struweel & punt & 114211 & 502821 \\
\hline 129 & Bunzing en wezel & Loofbos \& struweel & punt & 119227 & 493657 \\
\hline 150 & Bunzing en wezel & Rietland & punt & 114399 & 496981 \\
\hline 241 & Bunzing en wezel & Moeras en vochtige ruigte & punt & 117237 & 496068 \\
\hline 242 & Bunzing en wezel & Moeras en vochtige ruigte & punt & 116966 & 497373 \\
\hline 243 & Bunzing en wezel & Moeras en vochtige ruigte & punt & 117656 & 496903 \\
\hline 268 & Bunzing en wezel & Droge rietlanden en ruigte & punt & 116961 & 497410 \\
\hline 269 & Bunzing en wezel & Droge rietlanden en ruigte & punt & 112769 & 498940 \\
\hline 270 & Bunzing en wezel & Droge rietlanden en ruigte & punt & 111371 & 499877 \\
\hline 271 & Bunzing en wezel & Droge rietlanden en ruigte & punt & 111380 & 499866 \\
\hline 272 & Bunzing en wezel & Droge rietlanden en ruigte & punt & 112541 & 494651 \\
\hline 351 & Bunzing en wezel & Kruidenrijk grasland & punt & 117702 & 499007 \\
\hline 352 & Bunzing en wezel & Kruidenrijk grasland & punt & 112383 & 494156 \\
\hline 353 & Bunzing en wezel & Kruidenrijk grasland & punt & 109996 & 494494 \\
\hline 354 & Bunzing en wezel & Kruidenrijk grasland & punt & 108783 & 495269 \\
\hline 355 & Bunzing en wezel & Kruidenrijk grasland & punt & 108672 & 496470 \\
\hline 468 & Bunzing en wezel & Droog & punt & 112342 & 494073 \\
\hline 469 & Bunzing en wezel & Droog & punt & 113775 & 502331 \\
\hline 470 & Bunzing en wezel & Droog & punt & 113739 & 494163 \\
\hline 495 & Bunzing en wezel & Nat & punt & 118946 & 493142 \\
\hline 496 & Bunzing en wezel & Nat & punt & 116396 & 497471 \\
\hline 497 & Bunzing en wezel & Nat & punt & 113397 & 494241 \\
\hline 540 & Bunzing en wezel & Volkstuinen & punt & 113894 & 501456 \\
\hline 541 & Bunzing en wezel & Volkstuinen & punt & 118873 & 449538 \\
\hline 542 & Bunzing en wezel & Volkstuinen & punt & 118676 & 494959 \\
\hline 543 & Bunzing en wezel & Volkstuinen & punt & 117024 & 493527 \\
\hline 544 & Bunzing en wezel & Volkstuinen & punt & 114972 & 493789 \\
\hline 565 & Bunzing en wezel & Bouwland & punt & 108630 & 495476 \\
\hline 566 & Bunzing en wezel & Bouwland & punt & 108563 & 495820 \\
\hline 567 & Bunzing en wezel & Bouwland & punt & 108561 & 496295 \\
\hline 568 & Bunzing en wezel & Bouwland & punt & 108497 & 497086 \\
\hline 569 & Bunzing en wezel & Bouwland & punt & 108269 & 497579 \\
\hline 652 & Bunzing en wezel & Zoetwater & punt & 118039 & 498358 \\
\hline 653 & Bunzing en wezel & Zoetwater & punt & 117956 & 496200 \\
\hline 654 & Bunzing en wezel & Zoetwater & punt & 117412 & 496829 \\
\hline 655 & Bunzing en wezel & Zoetwater & punt & 117724 & 496913 \\
\hline 705 & Bunzing \& wezel & Kruidenrijkgras & punt & 114683 & 495704 \\
\hline 706 & Bunzing \& wezel & Kruidenrijkgras & punt & 113562 & 496554 \\
\hline 707 & Bunzing \& wezel & Kruidenrijkgras & punt & 113752 & 498714 \\
\hline 708 & Bunzing \& wezel & Kruidenrijkgras & punt & 117378 & 499154 \\
\hline 709 & Bunzing \& wezel & Kruidenrijkgras & punt & 113667 & 499452 \\
\hline 710 & Bunzing \& wezel & Moeras & punt & 114698 & 497451 \\
\hline 711 & Bunzing \& wezel & Moeras & punt & 112949 & 497977 \\
\hline 712 & Bunzing \& wezel & Moeras & punt & 114506 & 499541 \\
\hline
\end{tabular}




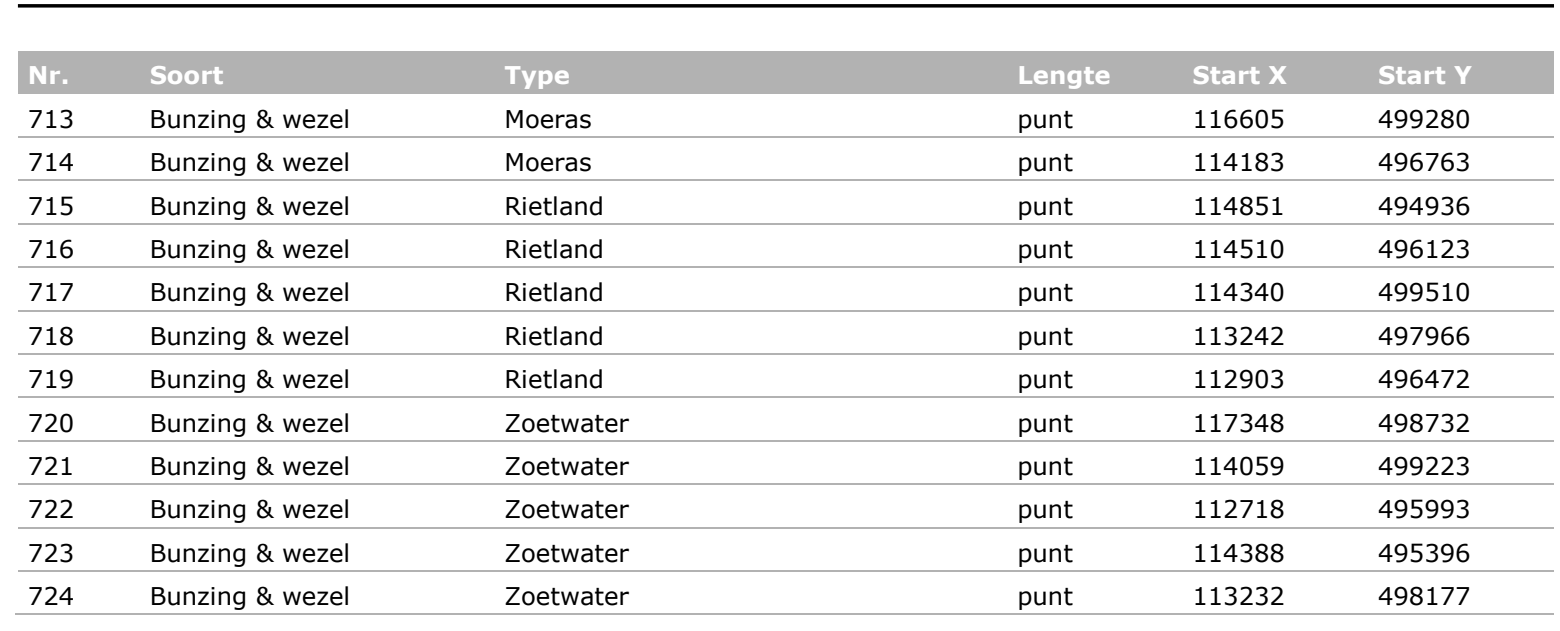
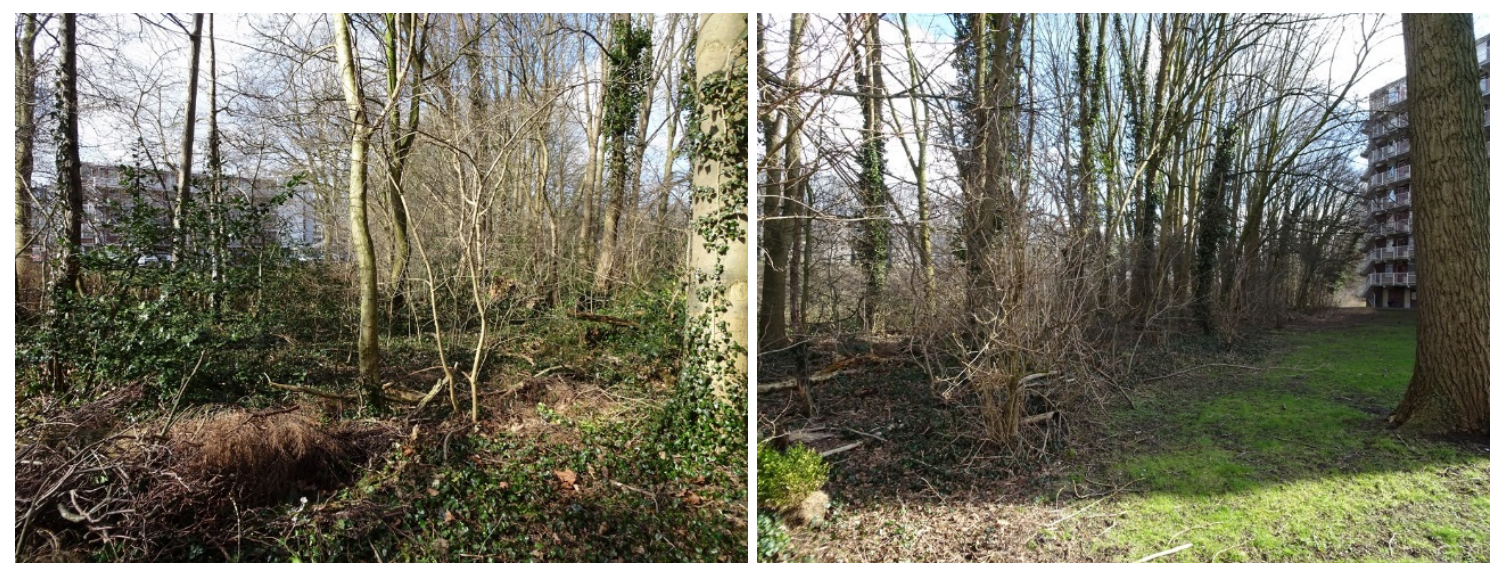

Figuur 13 Voorbeelden transecten in landschapstype 'Loofbos en struweel'. 


\section{Transecten dagvlinders}

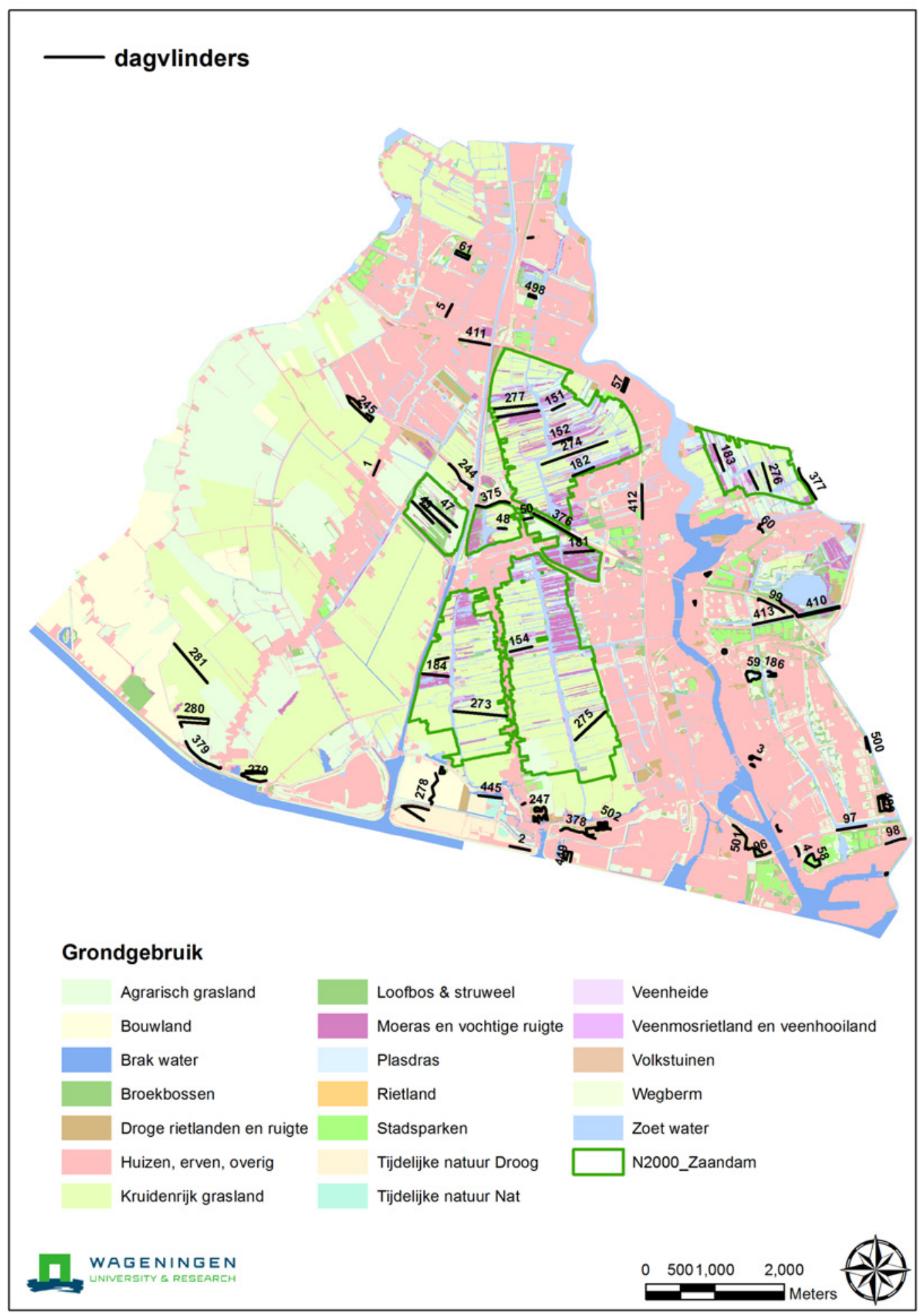

Figuur 14 Transecten voor dagvlinders. 
Tabel 8 Transecten voor dagvlinders.

\begin{tabular}{|c|c|c|c|c|c|c|c|}
\hline Nr. & Soort & Type & Lengte & Start X & Start Y & Eind $X$ & Eind $Y$ \\
\hline 46 & Dagvlinders & Broekbossen & 593 & 112220 & 498493 & 112652 & 498085 \\
\hline 47 & Dagvlinders & Broekbossen & 624 & 112282 & 498571 & 112750 & 498158 \\
\hline 48 & Dagvlinders & Broekbossen & 120 & 113347 & 498139 & 113467 & 498128 \\
\hline 49 & Dagvlinders & Broekbossen & 432 & 112407 & 498212 & 112107 & 498523 \\
\hline 50 & Dagvlinders & Broekbossen & 128 & 113717 & 498268 & 113844 & 498289 \\
\hline 151 & Dagvlinders & Veenmosrietland & 203 & 114129 & 499847 & 114312 & 499934 \\
\hline 152 & Dagvlinders & Veenmosrietland & 281 & 114146 & 499357 & 114411 & 499452 \\
\hline 153 & Dagvlinders & Veenmosrietland & 291 & 116968 & 498964 & 117096 & 498702 \\
\hline 154 & Dagvlinders & Veenmosrietland & 327 & 113837 & 496426 & 113518 & 496353 \\
\hline 155 & Dagvlinders & Veenmosrietland & 184 & 112447 & 496234 & 112628 & 496267 \\
\hline 181 & Dagvlinders & Moeras en vochtige ruigte & 426 & 114729 & 497813 & 114304 & 497781 \\
\hline 182 & Dagvlinders & Moeras en vochtige ruigte & 331 & 114422 & 498892 & 114728 & 499020 \\
\hline 183 & Dagvlinders & Moeras en vochtige ruigte & 404 & 116604 & 498968 & 116464 & 499347 \\
\hline 184 & Dagvlinders & Moeras en vochtige ruigte & 374 & 112257 & 496036 & 112629 & 496000 \\
\hline 185 & Dagvlinders & Moeras en vochtige ruigte & 599 & 113341 & 499743 & 113933 & 499836 \\
\hline 273 & Dagvlinders & Kruidenrijk grasland & 769 & 112700 & 495498 & 113465 & 495428 \\
\hline 274 & Dagvlinders & Kruidenrijk grasland & 1000 & 113977 & 499058 & 114921 & 499389 \\
\hline 275 & Dagvlinders & Kruidenrijk grasland & 604 & 114456 & 495079 & 114898 & 495491 \\
\hline 276 & Dagvlinders & Kruidenrijk grasland & 415 & 117283 & 498680 & 117161 & 499077 \\
\hline 277 & Dagvlinders & Kruidenrijk grasland & 612 & 113299 & 499862 & 113908 & 499921 \\
\hline 1 & Dagvlinders & Huizen, erven, overig & 225 & 111545 & 498906 & 111631 & 499113 \\
\hline 2 & Dagvlinders & Huizen, erven, overig & 290 & 113802 & 493490 & 113518 & 493547 \\
\hline 3 & Dagvlinders & Huizen, erven, overig & 153 & 116995 & 494848 & 117135 & 494795 \\
\hline 4 & Dagvlinders & Huizen, erven, overig & 150 & 117689 & 493407 & 117639 & 493543 \\
\hline 5 & Dagvlinders & Huizen, erven, overig & 199 & 112594 & 501192 & 112684 & 501370 \\
\hline 57 & Dagvlinders & Stadsparken & 439 & 115139 & 500160 & 115121 & 500131 \\
\hline 58 & Dagvlinders & Stadsparken & 625 & 117949 & 493352 & 117974 & 493360 \\
\hline 59 & Dagvlinders & Stadsparken & 617 & 117100 & 496043 & 117105 & 496053 \\
\hline 60 & Dagvlinders & Stadsparken & 204 & 117160 & 498198 & 117174 & 498078 \\
\hline 61 & Dagvlinders & Stadsparken & 477 & 112910 & 502081 & 112933 & 502071 \\
\hline 96 & Dagvlinders & Loofbos \& struweel & 465 & 117157 & 493459 & 117275 & 493459 \\
\hline 97 & Dagvlinders & Loofbos \& struweel & 421 & 118656 & 493844 & 118240 & 493781 \\
\hline 98 & Dagvlinders & Loofbos \& struweel & 296 & 119227 & 493657 & 118943 & 493581 \\
\hline 99 & Dagvlinders & Loofbos \& struweel & 440 & 117098 & 497098 & 117475 & 496926 \\
\hline 186 & Dagvlinders & Moeras en vochtige ruigte & 291 & 117237 & 496068 & 117246 & 496003 \\
\hline 187 & Dagvlinders & Moeras en vochtige ruigte & 318 & 117656 & 496903 & 117406 & 497094 \\
\hline 244 & Dagvlinders & Droge rietlanden en ruigte & 598 & 112636 & 499072 & 112922 & 498725 \\
\hline 245 & Dagvlinders & Droge rietlanden en ruigte & 961 & 111371 & 499877 & 111446 & 499789 \\
\hline 246 & Dagvlinders & Droge rietlanden en ruigte & 268 & 112541 & 494651 & 112562 & 494630 \\
\hline 247 & Dagvlinders & Droge rietlanden en ruigte & 1009 & 113934 & 493884 & 113980 & 494054 \\
\hline 278 & Dagvlinders & Kruidenrijk grasland & 532 & 112383 & 494156 & 112442 & 494600 \\
\hline 279 & Dagvlinders & Kruidenrijk grasland & 996 & 109996 & 494494 & 109706 & 494634 \\
\hline 280 & Dagvlinders & Kruidenrijk grasland & 985 & 108783 & 495269 & 108729 & 495415 \\
\hline 281 & Dagvlinders & Kruidenrijk grasland & 739 & 108672 & 496470 & 109150 & 495906 \\
\hline 375 & Dagvlinders & Wegberm & 504 & 113028 & 498466 & 113512 & 498501 \\
\hline 376 & Dagvlinders & Wegberm & 777 & 113860 & 498354 & 114533 & 497967 \\
\hline 377 & Dagvlinders & Wegberm & 521 & 117691 & 499006 & 117937 & 498559 \\
\hline 378 & Dagvlinders & Wegberm & 543 & 114250 & 493776 & 114751 & 493657 \\
\hline 379 & Dagvlinders & Wegberm & 671 & 108839 & 495062 & 109345 & 494683 \\
\hline 410 & Dagvlinders & Spoorberm & 632 & 118274 & 497009 & 117656 & 496876 \\
\hline 411 & Dagvlinders & Spoorberm & 443 & 112787 & 500863 & 113224 & 500790 \\
\hline 412 & Dagvlinders & Spoorberm & 487 & 115434 & 498279 & 115420 & 498766 \\
\hline 413 & Dagvlinders & Spoorberm & 582 & 117599 & 496865 & 117029 & 496744 \\
\hline 414 & Dagvlinders & Spoorberm & 612 & 117675 & 496858 & 118273 & 496988 \\
\hline 425 & Dagvlinders & Plantsoengras & 139 & 117050 & 494694 & 117038 & 494697 \\
\hline 426 & Dagvlinders & Plantsoengras & 142 & 116995 & 494848 & 116993 & 494840 \\
\hline 427 & Dagvlinders & Plantsoengras & 133 & 117431 & 493769 & 117377 & 493852 \\
\hline
\end{tabular}




\begin{tabular}{llllllll}
\hline Nr. & Soort & Type & Lengte & Start X & Start Y & Eind X & Eind Y \\
\hline 428 & Dagvlinders & Plantsoengras & 183 & 116631 & 496351 & 116642 & 496342 \\
\hline 429 & Dagvlinders & Plantsoengras & 115 & 116190 & 497027 & 116196 & 497056 \\
\hline 445 & Dagvlinders & Droog & 334 & 113397 & 494241 & 113065 & 494278 \\
\hline 446 & Dagvlinders & Droog & 759 & 112342 & 494073 & 112270 & 493915 \\
\hline 447 & Dagvlinders & Droog & 75 & 113775 & 502331 & 113849 & 502339 \\
\hline 448 & Dagvlinders & Droog & 50 & 113739 & 494168 & 113693 & 494148 \\
\hline 449 & Dagvlinders & Droog & 487 & 114384 & 493324 & 114351 & 493442 \\
\hline 471 & Dagvlinders & Nat & 106 & 118946 & 493142 & 118938 & 493130 \\
\hline 472 & Dagvlinders & Nat & 205 & 116396 & 497471 & 116384 & 497468 \\
\hline 498 & Dagvlinders & Volkstuinen & 242 & 113894 & 501456 & 113889 & 501488 \\
\hline 499 & Dagvlinders & Volkstuinen & 910 & 118857 & 494234 & 118895 & 494052 \\
\hline 500 & Dagvlinders & Volkstuinen & 391 & 118676 & 494959 & 118721 & 494910 \\
\hline 501 & Dagvlinders & Volkstuinen & 562 & 117024 & 493527 & 116736 & 493849 \\
\hline 502 & Dagvlinders & Volkstuinen & 997 & 114972 & 493789 & 114722 & 493710 \\
\hline
\end{tabular}
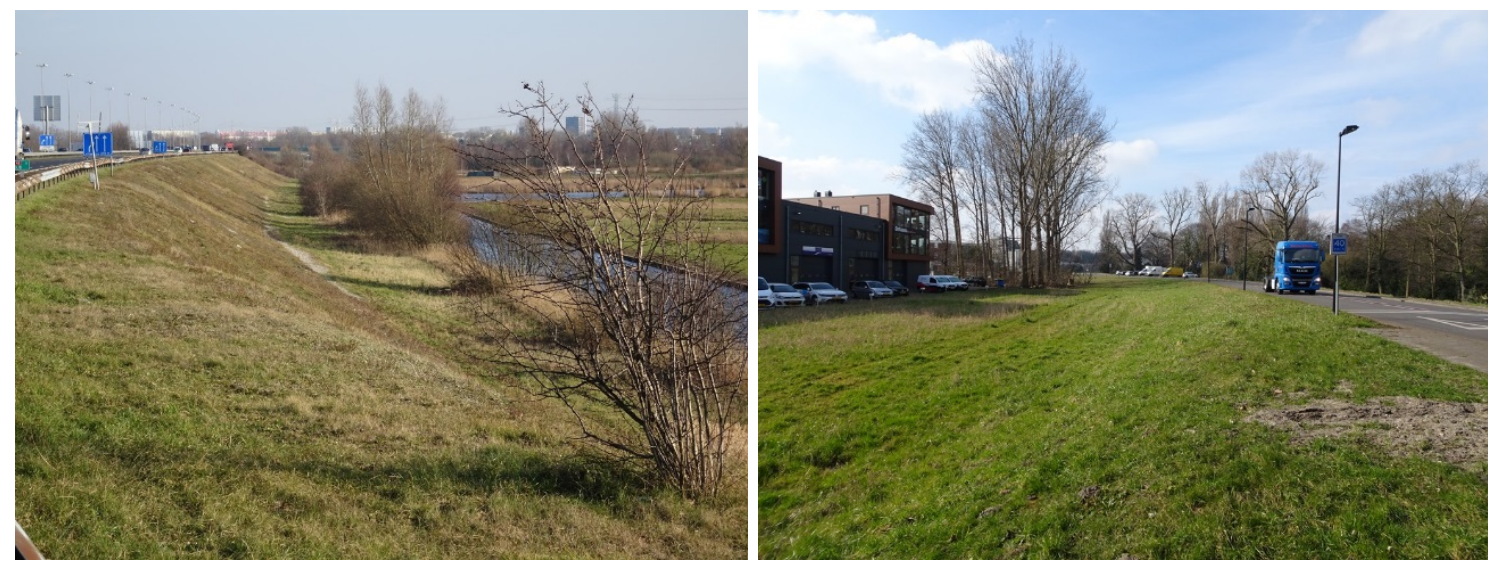

Figuur 15 Voorbeelden transecten in landschapstype 'Wegbermen'. 


\section{Transecten glassnijder}

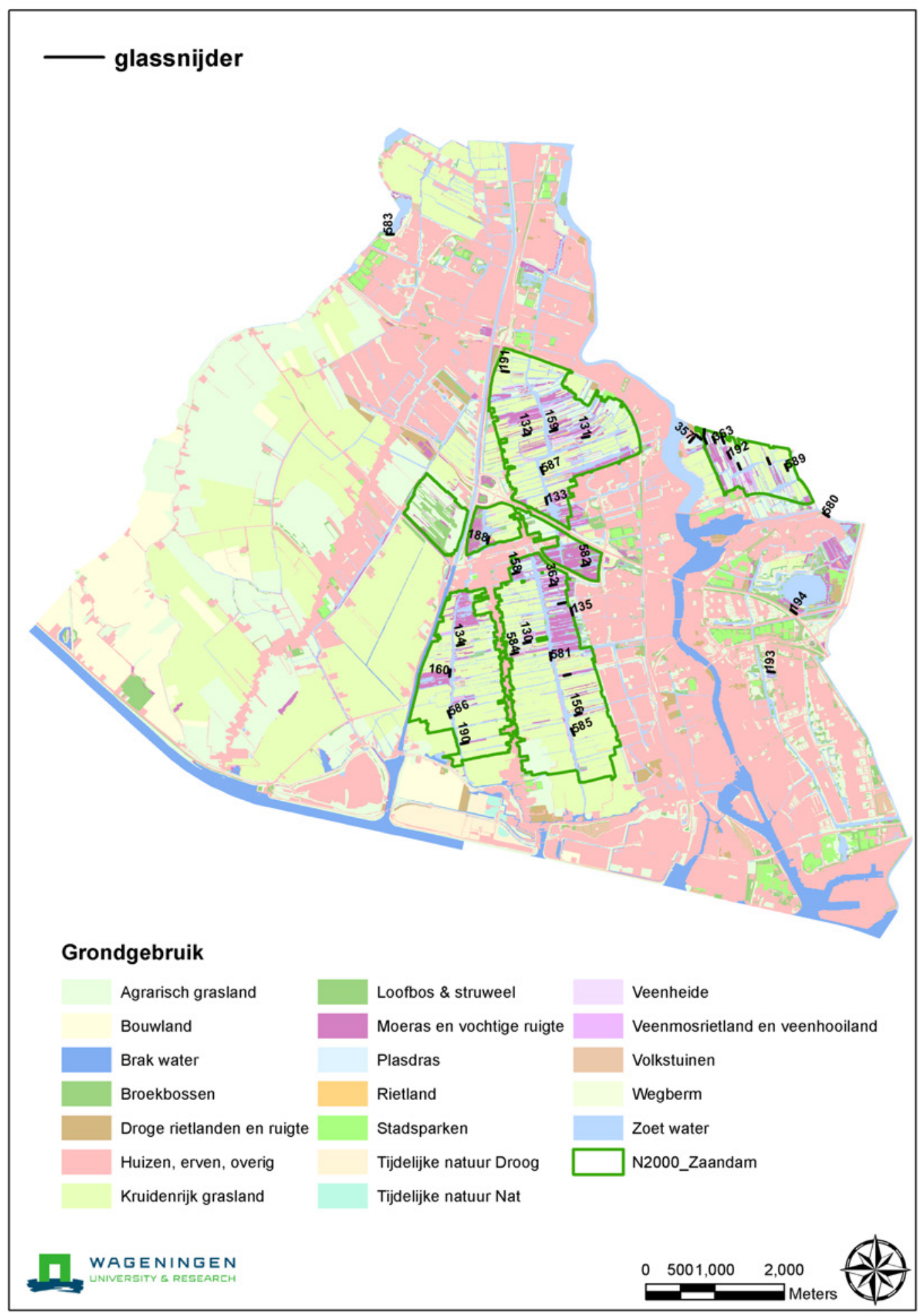

Figuur 16 Transecten voor glassnijder. 
Tabel 9 Transecten voor glassnijder.

\begin{tabular}{|c|c|c|c|c|c|c|c|}
\hline Nr. & Soort & Type & Lengte & Start X & Start Y & Eind $\mathbf{X}$ & Eind $Y$ \\
\hline 130 & Glassnijder & Rietland & 100 & 113714 & 496477 & 113812 & 496497 \\
\hline 131 & Glassnijder & Rietland & 100 & 114563 & 499441 & 114660 & 499464 \\
\hline 133 & Glassnijder & Rietland & 100 & 114034 & 498582 & 114058 & 498485 \\
\hline 134 & Glassnijder & Rietland & 100 & 112755 & 496442 & 112852 & 496465 \\
\hline 157 & Glassnijder & Veenmosrietland & 100 & 117230 & 499154 & 117269 & 499062 \\
\hline 158 & Glassnijder & Veenmosrietland & 100 & 113560 & 497480 & 113655 & 497509 \\
\hline 159 & Glassnijder & Veenmosrietland & 100 & 114102 & 499532 & 114197 & 499564 \\
\hline 160 & Glassnijder & Veenmosrietland & 100 & 112656 & 496098 & 112646 & 495999 \\
\hline 191 & Glassnijder & Moeras en vochtige ruigte & 100 & 113402 & 500405 & 113502 & 500396 \\
\hline 192 & Glassnijder & Moeras en vochtige ruigte & 100 & 116662 & 499237 & 116701 & 499145 \\
\hline 359 & Glassnijder & Plasdras & 100 & 116573 & 499459 & 116612 & 499367 \\
\hline 360 & Glassnijder & Plasdras & 100 & 116319 & 499455 & 116358 & 499363 \\
\hline 361 & Glassnijder & Plasdras & 100 & 114315 & 497068 & 114218 & 497045 \\
\hline 362 & Glassnijder & Plasdras & 100 & 114189 & 497331 & 114092 & 497308 \\
\hline 363 & Glassnijder & Plasdras & 100 & 116442 & 499462 & 116482 & 499370 \\
\hline 585 & Glassnijder & Zoetwater & 100 & 114405 & 495244 & 114444 & 495152 \\
\hline 586 & Glassnijder & Zoetwater & 100 & 112622 & 495497 & 112661 & 495405 \\
\hline 194 & Glassnijder & Moeras en vochtige ruigte & 100 & 117656 & 496903 & 117574 & 496961 \\
\hline 356 & Glassnijder & Plasdras & 100 & 116205 & 499488 & 116281 & 499423 \\
\hline 357 & Glassnijder & Plasdras & 100 & 116173 & 499456 & 116109 & 499379 \\
\hline 358 & Glassnijder & Plasdras & 100 & 116326 & 499564 & 116316 & 499465 \\
\hline 580 & Glassnijder & Zoetwater & 100 & 118039 & 498358 & 118122 & 498303 \\
\hline 581 & Glassnijder & Zoetwater & 100 & 114110 & 496237 & 114102 & 496337 \\
\hline 582 & Glassnijder & Zoetwater & 100 & 114559 & 497593 & 114657 & 497614 \\
\hline 583 & Glassnijder & Zoetwater & 100 & 111837 & 502382 & 111737 & 502382 \\
\hline 584 & Glassnijder & Zoetwater & 100 & 113534 & 496318 & 113630 & 496347 \\
\hline
\end{tabular}
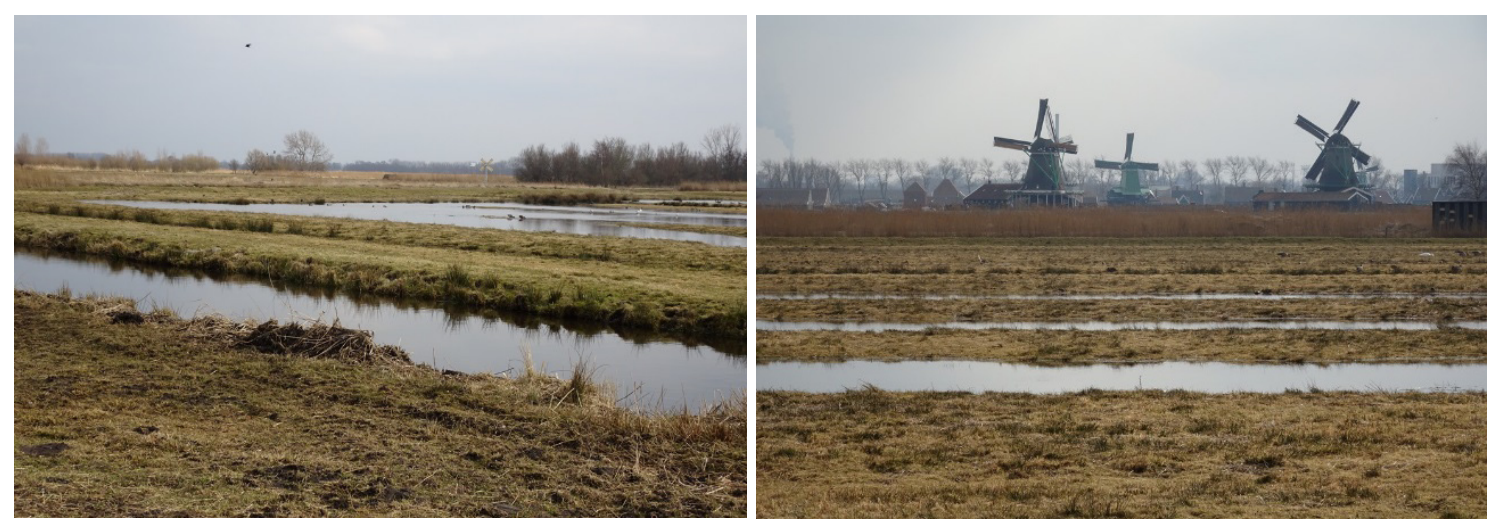

Figuur 17 Voorbeelden transecten in landschapstype 'Plasdras'. 


\section{Transecten moerassprinkhaan en veenmol}

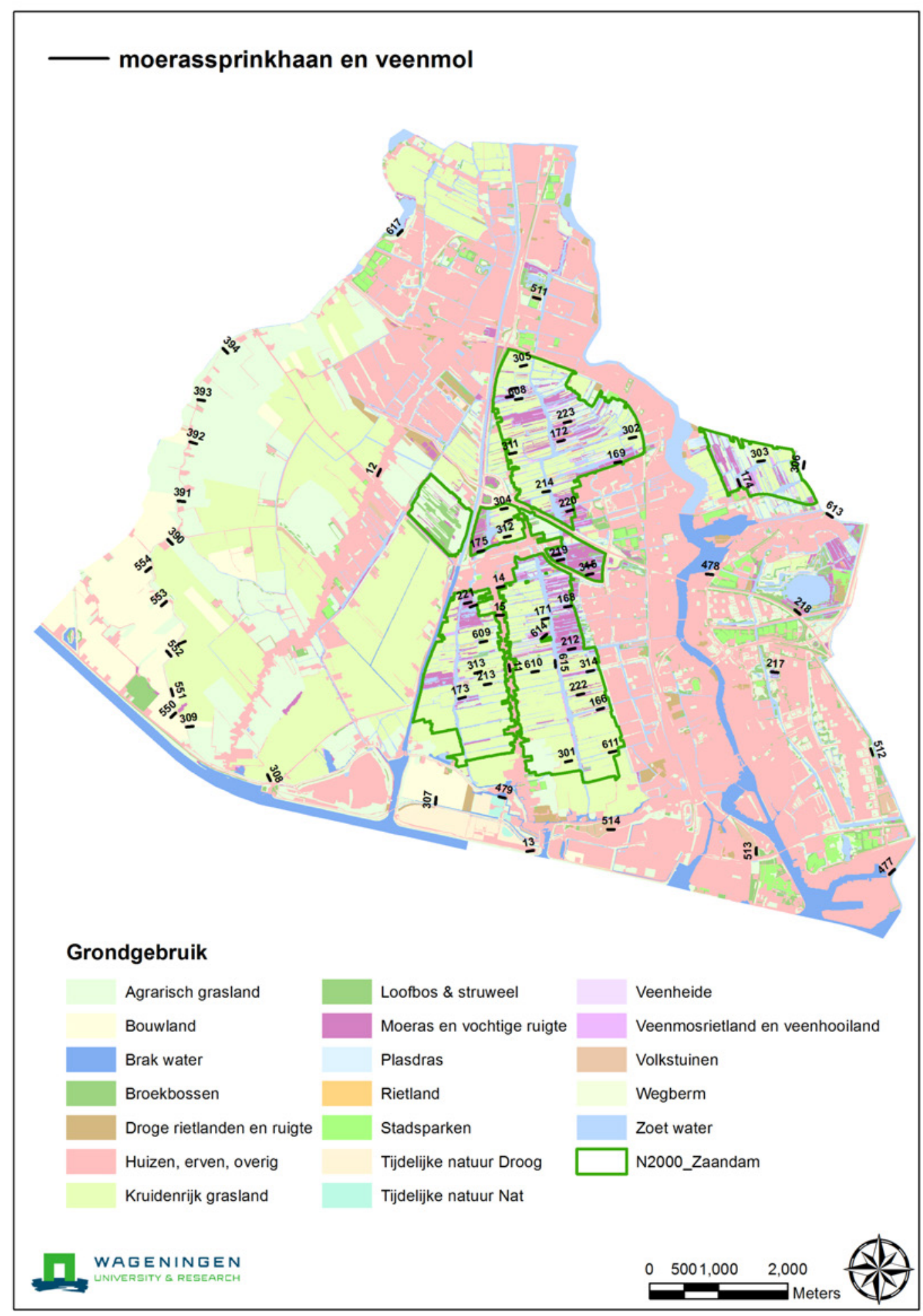

Figuur 18

Transecten voor moerassprinkhaan en veenmol. 
Tabel 10 Transecten voor moerassprinkhaan.

\begin{tabular}{|c|c|c|c|c|c|c|c|}
\hline Nr. & Soort & Type & Lengte & Start X & Start Y & Eind $\mathrm{X}$ & Eind $Y$ \\
\hline 166 & Moerassprinkhaan & Veenmosrietland & 100 & 114721 & 495517 & 114816 & 495547 \\
\hline 167 & Moerassprinkhaan & Veenmosrietland & 100 & 112884 & 497007 & 112979 & 497037 \\
\hline 168 & Moerassprinkhaan & Veenmosrietland & 100 & 114248 & 497003 & 114346 & 497022 \\
\hline 169 & Moerassprinkhaan & Veenmosrietland & 100 & 114973 & 499090 & 115071 & 499108 \\
\hline 170 & Moerassprinkhaan & Veenmosrietland & 100 & 113471 & 500159 & 113570 & 500178 \\
\hline 212 & Moerassprinkhaan & Moeras en vochtige ruigte & 100 & 114303 & 496390 & 114401 & 496409 \\
\hline 213 & Moerassprinkhaan & Moeras en vochtige ruigte & 100 & 113087 & 495882 & 113185 & 495901 \\
\hline 214 & Moerassprinkhaan & Moeras en vochtige ruigte & 100 & 113934 & 498666 & 114032 & 498684 \\
\hline 215 & Moerassprinkhaan & Moeras en vochtige ruigte & 100 & 113404 & 500037 & 113503 & 500056 \\
\hline 216 & Moerassprinkhaan & Moeras en vochtige ruigte & 100 & 114092 & 497754 & 114190 & 497773 \\
\hline 301 & Moerassprinkhaan & Kruidenrijk grasland & 100 & 114257 & 494767 & 114355 & 494786 \\
\hline 302 & Moerassprinkhaan & Kruidenrijk grasland & 100 & 115184 & 499447 & 115282 & 499465 \\
\hline 303 & Moerassprinkhaan & Kruidenrijk grasland & 100 & 117038 & 499108 & 117136 & 499126 \\
\hline 304 & Moerassprinkhaan & Kruidenrijk grasland & 100 & 113327 & 498419 & 113425 & 498438 \\
\hline 305 & Moerassprinkhaan & Kruidenrijk grasland & 100 & 113607 & 500485 & 113706 & 500504 \\
\hline 608 & Moerassprinkhaan & Zoetwater & 100 & 113538 & 500003 & 113636 & 500022 \\
\hline 609 & Moerassprinkhaan & Zoetwater & 100 & 113025 & 496494 & 113123 & 496513 \\
\hline 610 & Moerassprinkhaan & Zoetwater & 100 & 113776 & 496062 & 113874 & 496081 \\
\hline 611 & Moerassprinkhaan & Zoetwater & 100 & 114892 & 494903 & 114990 & 494922 \\
\hline 612 & Moerassprinkhaan & Zoetwater & 100 & 113388 & 498241 & 113484 & 498269 \\
\hline 11 & Veenmol & Huizen, erven, overig & 100 & 113443 & 496175 & 113459 & 496076 \\
\hline 12 & Veenmol & Huizen, erven, overig & 100 & 111545 & 498906 & 111589 & 498996 \\
\hline 13 & Veenmol & Huizen, erven, overig & 100 & 113802 & 493490 & 113704 & 493470 \\
\hline 14 & Veenmol & Huizen, erven, overig & 100 & 113276 & 497288 & 113374 & 497308 \\
\hline 15 & Veenmol & Huizen, erven, overig & 100 & 113265 & 496884 & 113365 & 496887 \\
\hline 217 & Moerassprinkhaan en Veenmol & Moeras en vochtige ruigte & 100 & 117237 & 496068 & 117337 & 496060 \\
\hline 218 & Moerassprinkhaan en Veenmol & Moeras en vochtige ruigte & 100 & 117656 & 496903 & 117577 & 496965 \\
\hline 306 & Moerassprinkhaan en Veenmol & Kruidenrijk grasland & 100 & 117702 & 499007 & 117714 & 499106 \\
\hline 307 & Moerassprinkhaan en Veenmol & Kruidenrijk grasland & 100 & 112383 & 494156 & 112392 & 494256 \\
\hline 308 & Moerassprinkhaan en Veenmol & Kruidenrijk grasland & 100 & 109996 & 494494 & 109953 & 494584 \\
\hline 309 & Moerassprinkhaan en Veenmol & Kruidenrijk grasland & 100 & 108783 & 495269 & 108882 & 495284 \\
\hline 310 & Moerassprinkhaan en Veenmol & Kruidenrijk grasland & 100 & 108672 & 496470 & 108763 & 496511 \\
\hline 390 & Veenmol & Agrarisch grasland & 100 & 108513 & 497986 & 108584 & 497915 \\
\hline 391 & Veenmol & Agrarisch grasland & 100 & 108660 & 498542 & 108759 & 498531 \\
\hline 392 & Veenmol & Agrarisch grasland & 100 & 108833 & 499395 & 108928 & 499365 \\
\hline 393 & Veenmol & Agrarisch grasland & 100 & 108946 & 500005 & 109045 & 499990 \\
\hline 394 & Veenmol & Agrarisch grasland & 100 & 109310 & 500746 & 109380 & 500675 \\
\hline 477 & Moerassprinkhaan & Nat & 100 & 118946 & 493142 & 119020 & 493210 \\
\hline 478 & Moerassprinkhaan & Nat & 100 & 116396 & 497471 & 116297 & 497483 \\
\hline 479 & Moerassprinkhaan & Nat & 100 & 113397 & 494241 & 113299 & 494263 \\
\hline 511 & Veenmol & Volkstuinen & 100 & 113894 & 501456 & 113799 & 501488 \\
\hline 512 & Veenmol & Volkstuinen & 100 & 118676 & 494959 & 118707 & 494864 \\
\hline 513 & Veenmol & Volkstuinen & 100 & 117024 & 493527 & 117025 & 493427 \\
\hline 514 & Veenmol & Volkstuinen & 100 & 114972 & 493789 & 114872 & 493789 \\
\hline 550 & Veenmol & Bouwland & 100 & 108630 & 495476 & 108556 & 495409 \\
\hline 551 & Veenmol & Bouwland & 100 & 108563 & 495820 & 108587 & 495723 \\
\hline 552 & Veenmol & Bouwland & 100 & 108561 & 496295 & 108496 & 496371 \\
\hline 553 & Veenmol & Bouwland & 100 & 108497 & 497086 & 108419 & 497024 \\
\hline 554 & Veenmol & Bouwland & 100 & 108269 & 497579 & 108191 & 497517 \\
\hline 613 & Moerassprinkhaan & Zoetwater & 100 & 118039 & 498358 & 118122 & 498302 \\
\hline 614 & Moerassprinkhaan & Zoetwater & 100 & 113993 & 496617 & 113915 & 496554 \\
\hline 615 & Moerassprinkhaan & Zoetwater & 100 & 114110 & 496237 & 114121 & 496138 \\
\hline 616 & Moerassprinkhaan & Zoetwater & 100 & 114559 & 497593 & 114657 & 497614 \\
\hline 617 & Moerassprinkhaan & Zoetwater & 100 & 111837 & 502382 & 111905 & 502455 \\
\hline 171 & Moerassprinkhaan en veenmol & Veenmosrietland & 100 & 113921 & 496821 & 114018 & 496846 \\
\hline 172 & Moerassprinkhaan en veenmol & Veenmosrietland & 100 & 114151 & 499395 & 114248 & 499420 \\
\hline 173 & Moerassprinkhaan en veenmol & Veenmosrietland & 100 & 112720 & 495681 & 112816 & 495705 \\
\hline
\end{tabular}




\begin{tabular}{llllllll}
\hline Nr. & Soort & Type & Lengte & Start X & Start Y & Eind X & Eind Y \\
\hline 174 & Moerassprinkhaan en veenmol & Veenmosrietland & 100 & 116751 & 498849 & 116790 & 498756 \\
\hline 175 & Moerassprinkhaan en veenmol & Veenmosrietland & 100 & 112990 & 497803 & 113087 & 497828 \\
\hline 219 & Moerassprinkhaan en veenmol & Moeras en vochtige ruigte & 100 & 114144 & 497674 & 114241 & 497699 \\
\hline 220 & Moerassprinkhaan en veenmol & Moeras en vochtige ruigte & 100 & 114279 & 498390 & 114376 & 498414 \\
\hline 221 & Moerassprinkhaan en veenmol & Moeras en vochtige ruigte & 100 & 112800 & 497052 & 112897 & 497077 \\
\hline 222 & Moerassprinkhaan en veenmol & Moeras en vochtige ruigte & 100 & 114430 & 495733 & 114527 & 495757 \\
\hline 223 & Moerassprinkhaan en veenmol & Moeras en vochtige ruigte & 100 & 114243 & 499669 & 114340 & 499694 \\
\hline 311 & Moerassprinkhaan en veenmol & Kruidenrijk grasland & 100 & 113450 & 499216 & 113547 & 499241 \\
\hline 312 & Moerassprinkhaan en veenmol & Kruidenrijk grasland & 100 & 113371 & 498010 & 113468 & 498035 \\
\hline 313 & Moerassprinkhaan en veenmol & Kruidenrijk grasland & 100 & 112952 & 496048 & 113048 & 496072 \\
\hline 314 & Moerassprinkhaan en veenmol & Kruidenrijk grasland & 100 & 114575 & 496069 & 114672 & 496093 \\
\hline 315 & Moerassprinkhaan en veenmol & Kruidenrijk grasland & 100 & 114563 & 497465 & 114660 & 497490 \\
\hline
\end{tabular}
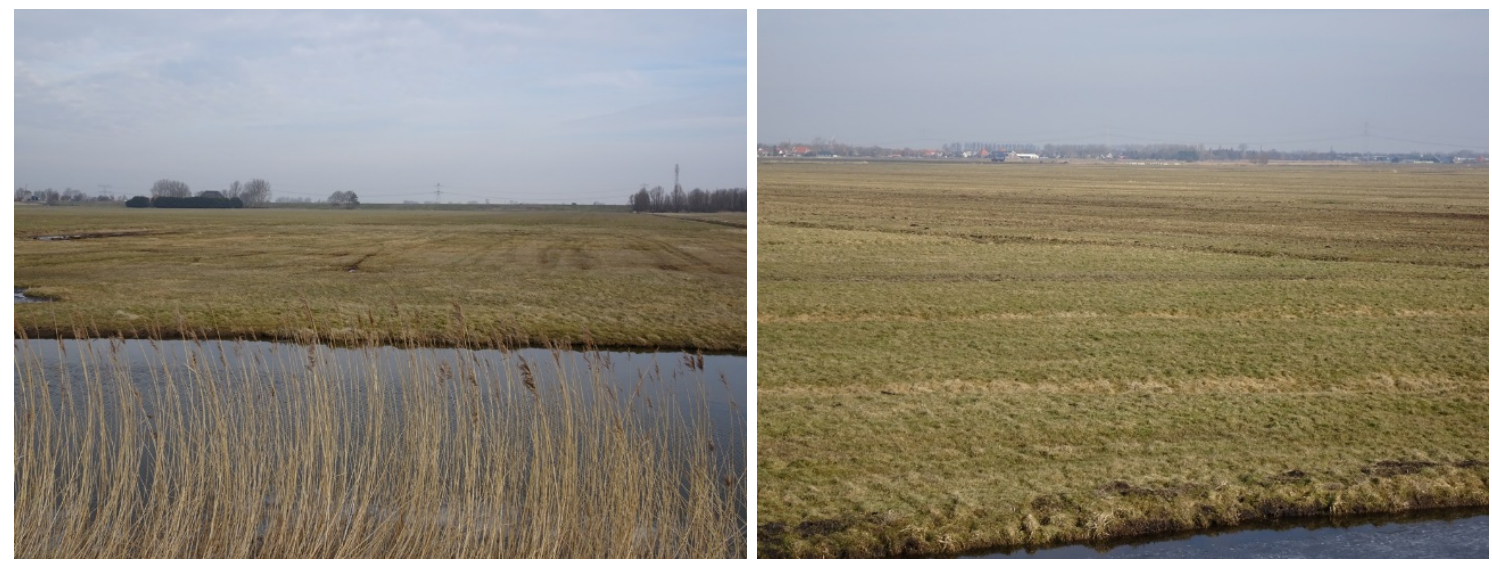

Figuur 19 Voorbeelden transecten in landschapstype 'Kruidenrijk grasland'. 


\section{Transecten wilde bijen}

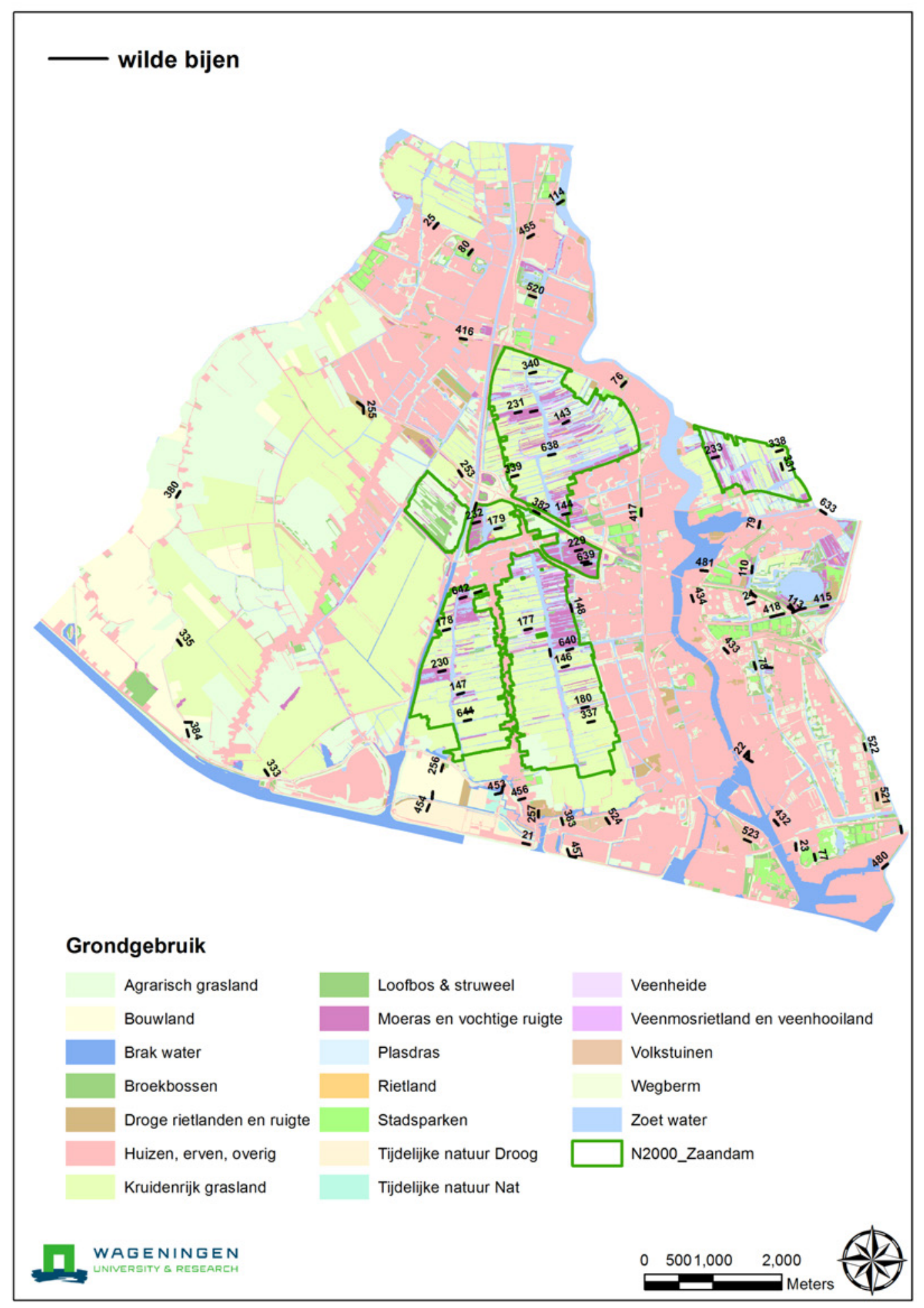

Figuur 20 Transecten voor wilde bijen. 
Tabel 11 Transecten voor wilde bijen.

\begin{tabular}{|c|c|c|c|c|c|c|c|}
\hline Nr. & Soort & Type & Lengte & Start X & Start Y & Eind $\mathbf{X}$ & Eind $Y$ \\
\hline 143 & Wilde bijen & Rietland & 100 & 114286 & 499621 & 114376 & 499663 \\
\hline 144 & Wilde bijen & Rietland & 100 & 114283 & 498293 & 114380 & 498318 \\
\hline 145 & Wilde bijen & Rietland & 100 & 113003 & 497155 & 113100 & 497180 \\
\hline 146 & Wilde bijen & Rietland & 100 & 114274 & 496070 & 114371 & 496095 \\
\hline 147 & Wilde bijen & Rietland & 100 & 112749 & 495675 & 112846 & 495700 \\
\hline 176 & Wilde bijen & Veenmosrietland & 100 & 113814 & 499788 & 113911 & 499813 \\
\hline 177 & Wilde bijen & Veenmosrietland & 100 & 113731 & 496612 & 113828 & 496636 \\
\hline 178 & Wilde bijen & Veenmosrietland & 100 & 112544 & 496604 & 112641 & 496628 \\
\hline 179 & Wilde bijen & Veenmosrietland & 100 & 113297 & 498084 & 113394 & 498108 \\
\hline 180 & Wilde bijen & Veenmosrietland & 100 & 114565 & 495475 & 114662 & 495499 \\
\hline 229 & Wilde bijen & Moeras en vochtige ruigte & 100 & 114470 & 497763 & 114567 & 497787 \\
\hline 230 & Wilde bijen & Moeras en vochtige ruigte & 100 & 112478 & 496003 & 112575 & 496028 \\
\hline 231 & Wilde bijen & Moeras en vochtige ruigte & 100 & 113586 & 499772 & 113683 & 499796 \\
\hline 232 & Wilde bijen & Moeras en vochtige ruigte & 100 & 112978 & 498168 & 113075 & 498193 \\
\hline 233 & Wilde bijen & Moeras en vochtige ruigte & 100 & 116463 & 499119 & 116560 & 499143 \\
\hline 336 & Wilde bijen & Kruidenrijk grasland & 100 & 112879 & 495413 & 112976 & 495438 \\
\hline 337 & Wilde bijen & Kruidenrijk grasland & 100 & 114651 & 495264 & 114748 & 495289 \\
\hline 338 & Wilde bijen & Kruidenrijk grasland & 100 & 117396 & 499213 & 117493 & 499238 \\
\hline 339 & Wilde bijen & Kruidenrijk grasland & 100 & 113539 & 498845 & 113636 & 498870 \\
\hline 340 & Wilde bijen & Kruidenrijk grasland & 100 & 113800 & 500350 & 113897 & 500374 \\
\hline 638 & Wilde bijen & Zoetwater & 100 & 114077 & 499156 & 114174 & 499181 \\
\hline 639 & Wilde bijen & Zoetwater & 100 & 114603 & 497560 & 114700 & 497585 \\
\hline 640 & Wilde bijen & Zoetwater & 100 & 114340 & 496318 & 114437 & 496342 \\
\hline 641 & Wilde bijen & Zoetwater & 100 & 112850 & 495286 & 112947 & 495310 \\
\hline 642 & Wilde bijen & Zoetwater & 100 & 112781 & 497073 & 112878 & 497097 \\
\hline 380 & Wilde bijen & Wegberm & 100 & 108653 & 498549 & 108709 & 498632 \\
\hline 21 & Wilde bijen & Huizen, erven, overig & 100 & 113802 & 493490 & 113704 & 493510 \\
\hline 22 & Wilde bijen & Huizen, erven, overig & 100 & 116995 & 494848 & 116931 & 494771 \\
\hline 23 & Wilde bijen & Huizen, erven, overig & 100 & 117689 & 493407 & 117679 & 493506 \\
\hline 24 & Wilde bijen & Huizen, erven, overig & 100 & 116984 & 496988 & 117079 & 497020 \\
\hline 76 & Wilde bijen & Stadsparken & 100 & 115139 & 500160 & 115207 & 500233 \\
\hline 77 & Wilde bijen & Stadsparken & 100 & 117949 & 493352 & 117972 & 493255 \\
\hline 78 & Wilde bijen & Stadsparken & 100 & 117100 & 496043 & 117075 & 496140 \\
\hline 79 & Wilde bijen & Stadsparken & 100 & 117160 & 498198 & 117140 & 498100 \\
\hline 80 & Wilde bijen & Stadsparken & 100 & 112910 & 502081 & 112974 & 502158 \\
\hline 110 & Wilde bijen & Loofbos \& struweel & 100 & 117037 & 497444 & 117051 & 497543 \\
\hline 111 & Wilde bijen & Loofbos \& struweel & 100 & 119227 & 493657 & 119207 & 493755 \\
\hline 112 & Wilde bijen & Loofbos \& struweel & 100 & 117098 & 497098 & 117023 & 497164 \\
\hline 113 & Wilde bijen & Loofbos \& struweel & 100 & 117652 & 496895 & 117568 & 496949 \\
\hline 114 & Wilde bijen & Loofbos \& struweel & 100 & 114211 & 502821 & 114296 & 502873 \\
\hline 148 & Wilde bijen & Rietland & 100 & 114426 & 496885 & 114399 & 496981 \\
\hline 234 & Wilde bijen & Moeras en vochtige ruigte & 100 & 117237 & 496068 & 117337 & 496066 \\
\hline 235 & Wilde bijen & Moeras en vochtige ruigte & 100 & 117656 & 496903 & 117599 & 496985 \\
\hline 253 & Wilde bijen & Droge rietlanden en ruigte & 100 & 112769 & 498940 & 112825 & 498857 \\
\hline 254 & Wilde bijen & Droge rietlanden en ruigte & 100 & 111371 & 499877 & 111290 & 499935 \\
\hline 255 & Wilde bijen & Droge rietlanden en ruigte & 100 & 111380 & 499866 & 111388 & 499766 \\
\hline 256 & Wilde bijen & Droge rietlanden en ruigte & 100 & 112541 & 494651 & 112515 & 494555 \\
\hline 257 & Wilde bijen & Droge rietlanden en ruigte & 100 & 113934 & 493884 & 113934 & 493984 \\
\hline 331 & Wilde bijen & Kruidenrijk grasland & 100 & 117492 & 498949 & 117461 & 499044 \\
\hline 332 & Wilde bijen & Kruidenrijk grasland & 100 & 112383 & 494156 & 112392 & 494256 \\
\hline 333 & Wilde bijen & Kruidenrijk grasland & 100 & 109996 & 494494 & 109944 & 494580 \\
\hline 334 & Wilde bijen & Kruidenrijk grasland & 100 & 108783 & 495269 & 108883 & 495270 \\
\hline 335 & Wilde bijen & Kruidenrijk grasland & 100 & 108672 & 496470 & 108730 & 496389 \\
\hline 381 & Wilde bijen & Wegberm & 100 & 113028 & 498466 & 113000 & 498370 \\
\hline 382 & Wilde bijen & Wegberm & 100 & 113860 & 498354 & 113948 & 498307 \\
\hline 383 & Wilde bijen & Wegberm & 100 & 114295 & 493780 & 114262 & 493875 \\
\hline 384 & Wilde bijen & Wegberm & 100 & 108839 & 495062 & 108812 & 495158 \\
\hline
\end{tabular}




\begin{tabular}{|c|c|c|c|c|c|c|c|}
\hline Nr. & Soort & Type & Lengte & Start X & Start Y & Eind $\mathrm{X}$ & Eind $Y$ \\
\hline 415 & Wilde bijen & Spoorberm & 100 & 118046 & 496950 & 118144 & 496971 \\
\hline 416 & Wilde bijen & Spoorberm & 100 & 112787 & 500863 & 112886 & 500847 \\
\hline 417 & Wilde bijen & Spoorberm & 100 & 115434 & 498279 & 115432 & 498379 \\
\hline 418 & Wilde bijen & Spoorberm & 100 & 117412 & 496829 & 117316 & 496801 \\
\hline 419 & Wilde bijen & Spoorberm & 100 & 117724 & 496913 & 117635 & 496867 \\
\hline 430 & Wilde bijen & Plantsoengras & 100 & 117050 & 494694 & 116963 & 494743 \\
\hline 431 & Wilde bijen & Plantsoengras & 100 & 116995 & 494848 & 116988 & 494748 \\
\hline 432 & Wilde bijen & Plantsoengras & 100 & 117431 & 493769 & 117364 & 493843 \\
\hline 433 & Wilde bijen & Plantsoengras & 100 & 116631 & 496351 & 116699 & 496277 \\
\hline 434 & Wilde bijen & Plantsoengras & 100 & 116190 & 497027 & 116161 & 497123 \\
\hline 453 & Wilde bijen & Droog & 100 & 113397 & 494241 & 113299 & 494222 \\
\hline 454 & Wilde bijen & Droog & 100 & 112342 & 494073 & 112305 & 493980 \\
\hline 455 & Wilde bijen & Droog & 100 & 113775 & 502331 & 113863 & 502379 \\
\hline 456 & Wilde bijen & Droog & 100 & 113739 & 494163 & 113642 & 494137 \\
\hline 457 & Wilde bijen & Droog & 100 & 114384 & 493324 & 114354 & 493419 \\
\hline 480 & Wilde bijen & Nat & 100 & 118946 & 493142 & 119021 & 493208 \\
\hline 481 & Wilde bijen & Nat & 100 & 116396 & 497471 & 116297 & 497482 \\
\hline 482 & Wilde bijen & Nat & 100 & 113397 & 494241 & 113419 & 494339 \\
\hline 483 & Wilde bijen & Nat & 100 & 114384 & 493324 & 114482 & 493302 \\
\hline 520 & Wilde bijen & Volkstuinen & 100 & 113894 & 501456 & 113800 & 501489 \\
\hline 521 & Wilde bijen & Volkstuinen & 100 & 118857 & 494234 & 118871 & 494135 \\
\hline 522 & Wilde bijen & Volkstuinen & 100 & 118676 & 494959 & 118703 & 494863 \\
\hline 523 & Wilde bijen & Volkstuinen & 100 & 117024 & 493527 & 116931 & 493563 \\
\hline 524 & Wilde bijen & Volkstuinen & 100 & 114972 & 493789 & 114916 & 493872 \\
\hline 633 & Wilde bijen & Zoetwater & 100 & 118039 & 498358 & 118122 & 498303 \\
\hline 634 & Wilde bijen & Zoetwater & 100 & 117412 & 496829 & 117510 & 496851 \\
\hline 635 & Wilde bijen & Zoetwater & 100 & 117724 & 496913 & 117822 & 496933 \\
\hline 636 & Wilde bijen & Zoetwater & 100 & 114110 & 496237 & 114094 & 496336 \\
\hline 637 & Wilde bijen & Zoetwater & 100 & 114559 & 497593 & 114657 & 497612 \\
\hline 25 & Wilde bijen & Huizen, erven, overig & 100 & 112405 & 502466 & 112471 & 502541 \\
\hline
\end{tabular}

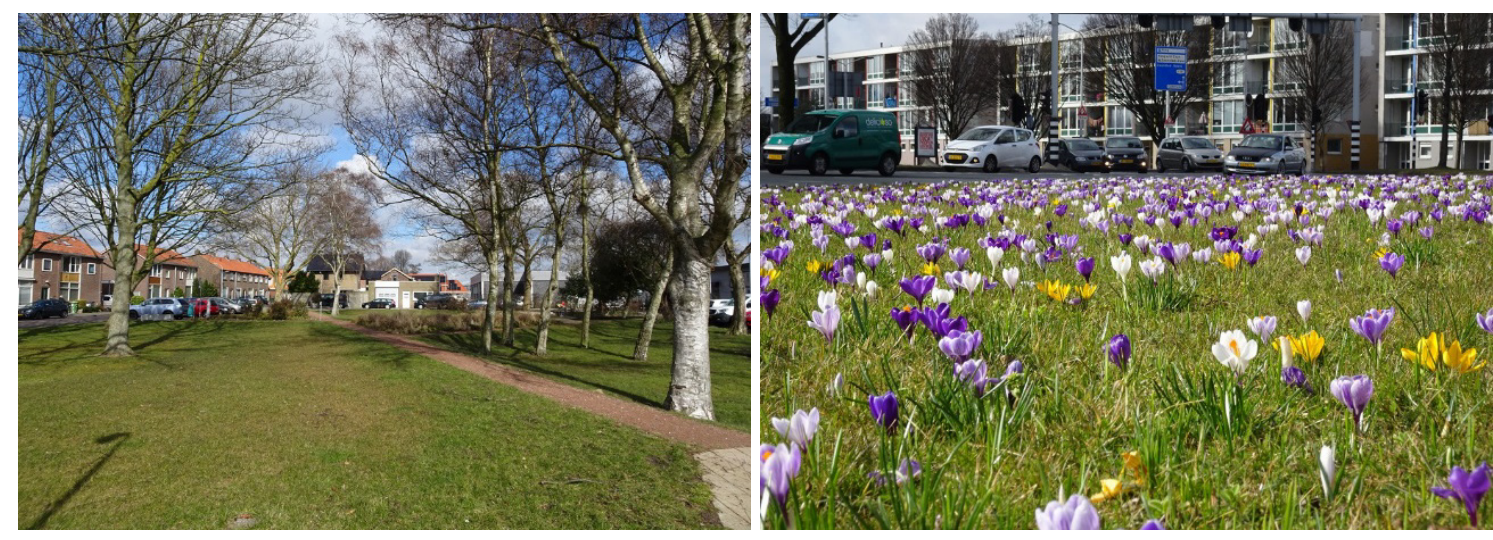

Figuur 21 Voorbeelden transecten in landschapstype 'Plantsoengras'. 


\section{Transecten en meetpunten broedvogels}

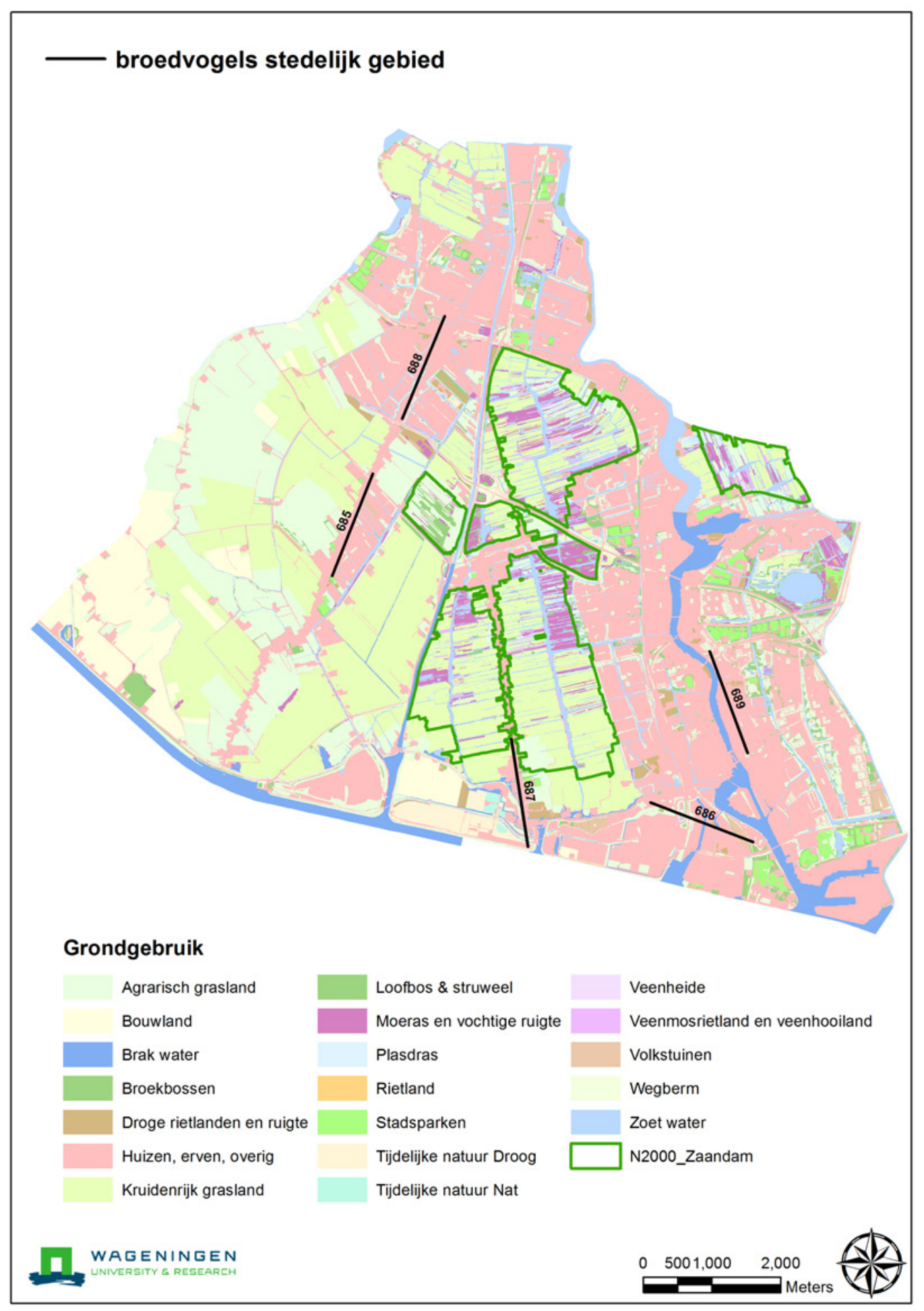

Figuur 22. Transecten voor broedvogels in stedelijk gebied. 
Tabel 12 Transecten voor broedvogels in stedelijk gebied.

\begin{tabular}{llllllll} 
Nr. & Soort & Type & Lengte & Start X & Start Y & Eind X \\
\hline 685 & Broedvogels & Huizen, erven, overig & 1593 & 111545 & 498906 & 110957 & 497425 \\
\hline 686 & Broedvogels & Huizen, erven, overig & 1592 & 117072 & 493551 & 115586 & 494125 \\
\hline 687 & Broedvogels & Huizen, erven, overig & 1577 & 113802 & 493490 & 113558 & 495048 \\
\hline 688 & Broedvogels & Huizen, erven, overig & 1609 & 112594 & 501192 & 111973 & 499708 \\
\hline 689 & Broedvogels & Huizen, erven, overig & 1576 & 116995 & 494848 & 116443 & 496324 \\
\hline
\end{tabular}
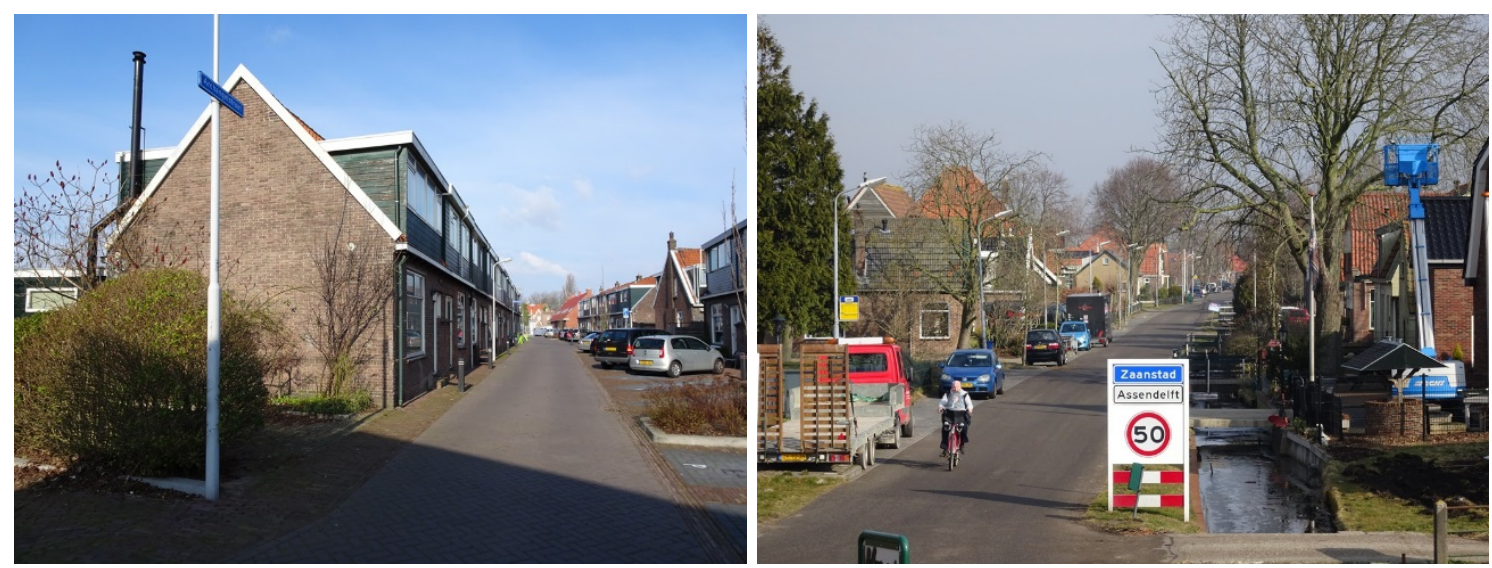

Figuur 23 Voorbeelden transecten in landschapstype 'Huizen, erven, overig'. 


\section{- broedvogels}

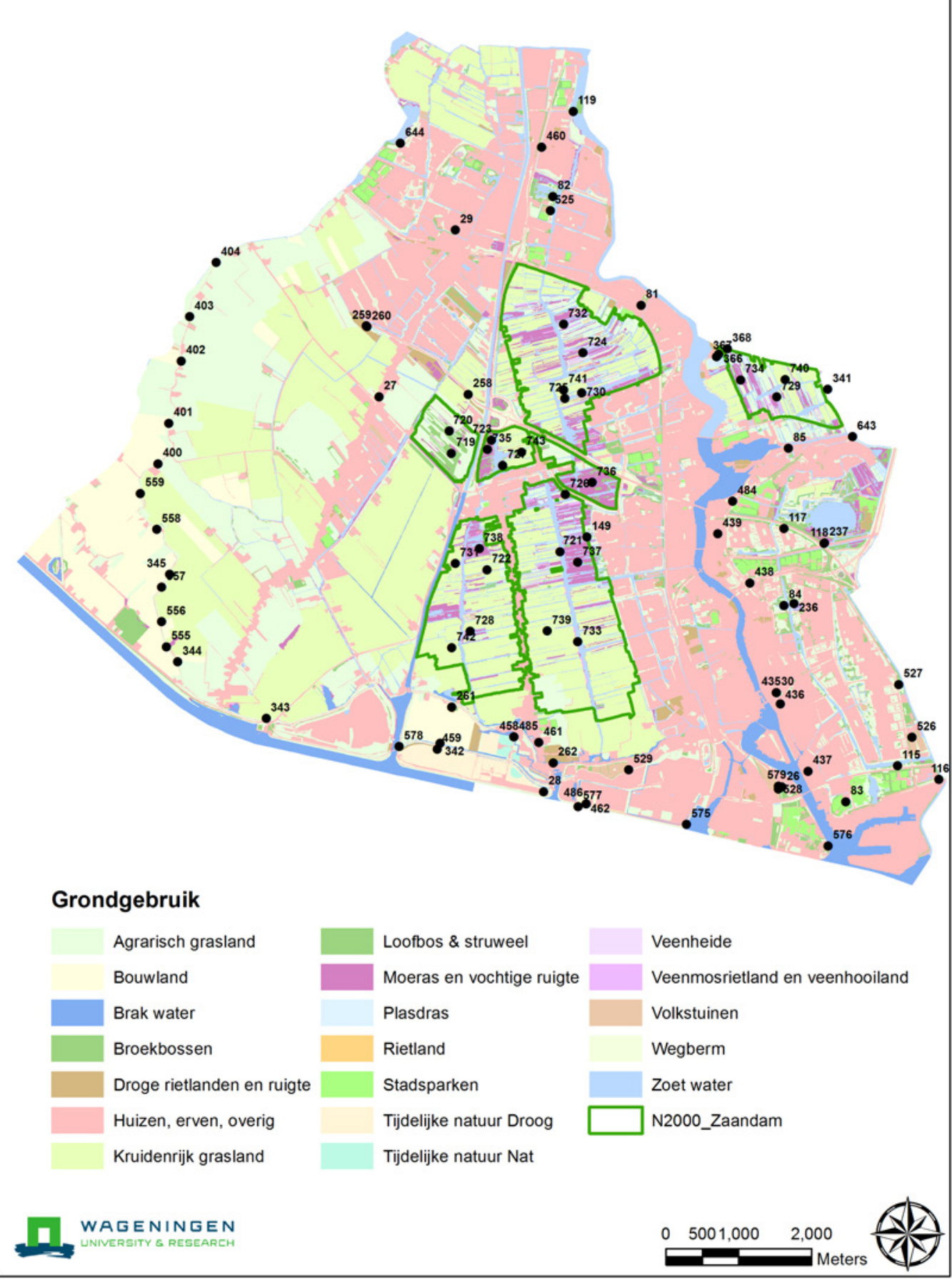

Figuur 24 Meetpunten voor broedvogels. 
Tabel 13 Meetpunten voor broedvogels.

\begin{tabular}{|c|c|c|c|c|c|}
\hline Nr. & Soort & Type & Lengte & Start X & Start Y \\
\hline 81 & Broedvogels & Stadsparken & telgebied & 115139 & 500160 \\
\hline 82 & Broedvogels & Stadsparken & telgebied & 113931 & 501653 \\
\hline 83 & Broedvogels & Stadsparken & telgebied & 117949 & 493352 \\
\hline 84 & Broedvogels & Stadsparken & telgebied & 117100 & 496043 \\
\hline 85 & Broedvogels & Stadsparken & telgebied & 117160 & 498198 \\
\hline 115 & Broedvogels & Loofbos \& struweel & telgebied & 118656 & 493844 \\
\hline 116 & Broedvogels & Loofbos \& struweel & telgebied & 119227 & 493657 \\
\hline 117 & Broedvogels & Loofbos \& struweel & telgebied & 117098 & 497098 \\
\hline 118 & Broedvogels & Loofbos \& struweel & telgebied & 117652 & 496895 \\
\hline 119 & Broedvogels & Loofbos \& struweel & telgebied & 114211 & 502821 \\
\hline 149 & Broedvogels & Rietland & telgebied & 114399 & 496981 \\
\hline 236 & Broedvogels & Moeras en vochtige ruigte & telgebied & 117237 & 496068 \\
\hline 237 & Broedvogels & Moeras en vochtige ruigte & telgebied & 117656 & 496903 \\
\hline 258 & Broedvogels & Droge rietlanden en ruigte & telgebied & 112769 & 498940 \\
\hline 259 & Broedvogels & Droge rietlanden en ruigte & telgebied & 111371 & 499877 \\
\hline 260 & Broedvogels & Droge rietlanden en ruigte & telgebied & 111380 & 499866 \\
\hline 261 & Broedvogels & Droge rietlanden en ruigte & telgebied & 112541 & 494651 \\
\hline 262 & Broedvogels & Droge rietlanden en ruigte & telgebied & 113934 & 493884 \\
\hline 341 & Broedvogels & Kruidenrijk grasland & telgebied & 117702 & 499007 \\
\hline 342 & Broedvogels & Kruidenrijk grasland & telgebied & 112383 & 494156 \\
\hline 343 & Broedvogels & Kruidenrijk grasland & telgebied & 109996 & 494494 \\
\hline 344 & Broedvogels & Kruidenrijk grasland & telgebied & 108783 & 495269 \\
\hline 345 & Broedvogels & Kruidenrijk grasland & telgebied & 108672 & 496470 \\
\hline 366 & Broedvogels & Plasdras & telgebied & 116205 & 499488 \\
\hline 367 & Broedvogels & Plasdras & telgebied & 116173 & 499456 \\
\hline 368 & Broedvogels & Plasdras & telgebied & 116326 & 499564 \\
\hline 400 & Broedvogels & Agrarisch grasland & telgebied & 108513 & 497986 \\
\hline 401 & Broedvogels & Agrarisch grasland & telgebied & 108660 & 498542 \\
\hline 402 & Broedvogels & Agrarisch grasland & telgebied & 108833 & 499395 \\
\hline 403 & Broedvogels & Agrarisch grasland & telgebied & 108946 & 500005 \\
\hline 404 & Broedvogels & Agrarisch grasland & telgebied & 109310 & 500746 \\
\hline 435 & Broedvogels & Plantsoengras & telgebied & 116995 & 494848 \\
\hline 436 & Broedvogels & Plantsoengras & telgebied & 117050 & 494694 \\
\hline 437 & Broedvogels & Plantsoengras & telgebied & 117431 & 493769 \\
\hline 438 & Broedvogels & Plantsoengras & telgebied & 116631 & 496351 \\
\hline 439 & Broedvogels & Plantsoengras & telgebied & 116190 & 497027 \\
\hline 458 & Broedvogels & Droog & telgebied & 113397 & 494241 \\
\hline 459 & Broedvogels & Droog & telgebied & 112342 & 494073 \\
\hline 460 & Broedvogels & Droog & telgebied & 113775 & 502331 \\
\hline 461 & Broedvogels & Droog & telgebied & 113739 & 494163 \\
\hline 462 & Broedvogels & Droog & telgebied & 114384 & 493324 \\
\hline 484 & Broedvogels & Nat & telgebied & 116396 & 497471 \\
\hline 485 & Broedvogels & Nat & telgebied & 113397 & 494241 \\
\hline 486 & Broedvogels & Nat & telgebied & 114384 & 493324 \\
\hline 525 & Broedvogels & Volkstuinen & telgebied & 113894 & 501456 \\
\hline 526 & Broedvogels & Volkstuinen & telgebied & 118873 & 449538 \\
\hline 527 & Broedvogels & Volkstuinen & telgebied & 118676 & 494959 \\
\hline 528 & Broedvogels & Volkstuinen & telgebied & 117024 & 493527 \\
\hline 529 & Broedvogels & Volkstuinen & telgebied & 114972 & 493789 \\
\hline 555 & Broedvogels & Bouwland & telgebied & 108630 & 495476 \\
\hline 556 & Broedvogels & Bouwland & telgebied & 108563 & 495820 \\
\hline 557 & Broedvogels & Bouwland & telgebied & 108561 & 496295 \\
\hline 558 & Broedvogels & Bouwland & telgebied & 108497 & 497086 \\
\hline 559 & Broedvogels & Bouwland & telgebied & 108269 & 497579 \\
\hline 575 & Broedvogels & Brakwater & telgebied & 115763 & 493040 \\
\hline 576 & Broedvogels & Brakwater & telgebied & 117704 & 492746 \\
\hline 577 & Broedvogels & Brakwater & telgebied & 114278 & 493284 \\
\hline
\end{tabular}




\begin{tabular}{|c|c|c|c|c|c|}
\hline Nr. & Soort & Type & Lengte & Start X & Start Y \\
\hline 578 & Broedvogels & Brakwater & telgebied & 111819 & 494107 \\
\hline 579 & Broedvogels & Brakwater & telgebied & 117025 & 493565 \\
\hline 643 & Broedvogels & Zoetwater & telgebied & 118039 & 498358 \\
\hline 644 & Broedvogels & Zoetwater & telgebied & 111837 & 502382 \\
\hline 719 & Broedvogels & Broekbos & telgebied & 112536 & 498131 \\
\hline 720 & Broedvogels & Broekbos & telgebied & 112509 & 498435 \\
\hline 721 & Broedvogels & Broekbos & telgebied & 114029 & 496782 \\
\hline 722 & Broedvogels & Broekbos & telgebied & 113026 & 496534 \\
\hline 723 & Broedvogels & Broekbos & telgebied & 113089 & 498312 \\
\hline 724 & Broedvogels & Rietland & telgebied & 114344 & 499509 \\
\hline 725 & Broedvogels & Rietland & telgebied & 114093 & 498880 \\
\hline 726 & Broedvogels & Rietland & telgebied & 114100 & 497565 \\
\hline 727 & Broedvogels & Rietland & telgebied & 113242 & 497965 \\
\hline 728 & Broedvogels & Rietland & telgebied & 112794 & 495687 \\
\hline 729 & Broedvogels & Veenmosrietland & telgebied & 117000 & 498903 \\
\hline 730 & Broedvogels & Veenmosrietland & telgebied & 114328 & 498962 \\
\hline 731 & Broedvogels & Veenmosrietland & telgebied & 112590 & 496618 \\
\hline 732 & Broedvogels & Veenmosrietland & telgebied & 114075 & 499899 \\
\hline 733 & Broedvogels & Veenmosrietland & telgebied & 114271 & 495545 \\
\hline 734 & Broedvogels & Moeras & telgebied & 116503 & 499137 \\
\hline 735 & Broedvogels & Moeras & telgebied & 113033 & 498186 \\
\hline 736 & Broedvogels & Moeras & telgebied & 114470 & 497730 \\
\hline 737 & Broedvogels & Moeras & telgebied & 114272 & 496636 \\
\hline 738 & Broedvogels & Moeras & telgebied & 112919 & 496821 \\
\hline 739 & Broedvogels & Kruidenrijkgrasland & telgebied & 113853 & 495695 \\
\hline 740 & Broedvogels & Kruidenrijkgrasland & telgebied & 117115 & 499144 \\
\hline 741 & Broedvogels & Kruidenrijkgrasland & telgebied & 114076 & 499000 \\
\hline 742 & Broedvogels & Kruidenrijkgrasland & telgebied & 112544 & 495463 \\
\hline 743 & Broedvogels & Kruidenrijkgrasland & telgebied & 113501 & 498146 \\
\hline
\end{tabular}

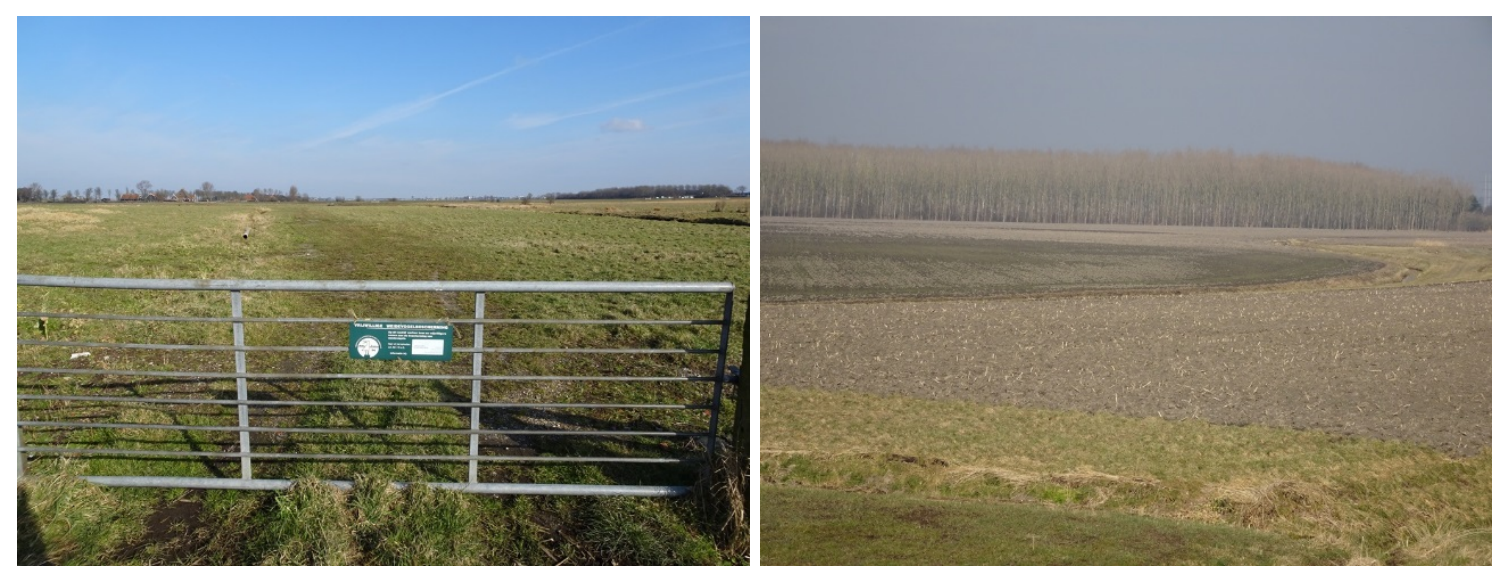

Figuur 25 Voorbeelden transecten in landschapstype 'Kruidenrijk grasland' (links) en 'Bouwland' (rechts). 


\section{Meetpunten planten}

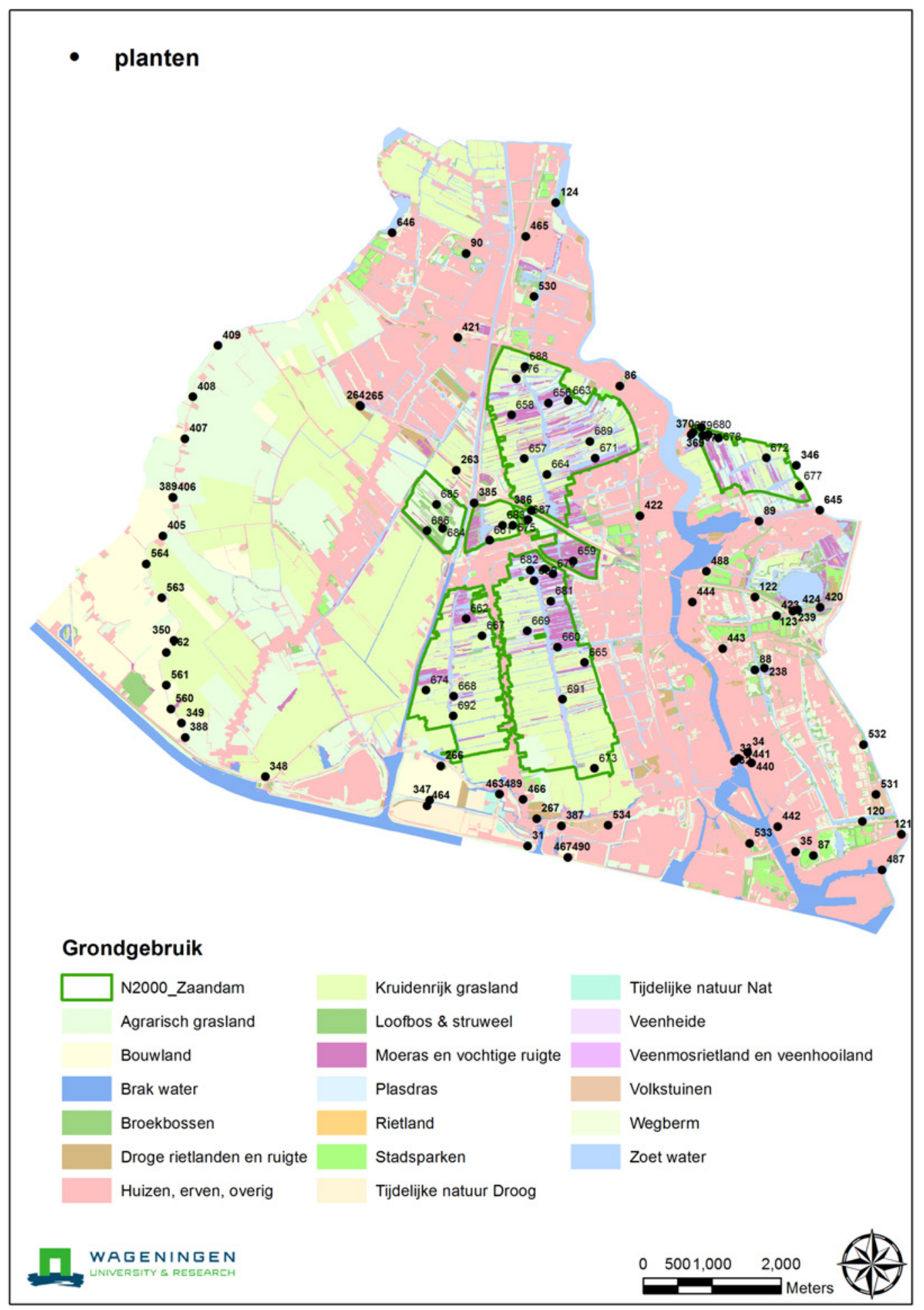

Figuur 26 Meetpunten voor planten. 
Tabel 14 Meetpunten voor planten.

\begin{tabular}{|c|c|c|c|c|c|}
\hline Nr. & Soort & Type & Lengte & Start X & Start Y \\
\hline 31 & Planten & Huizen, erven, overig & $\mathrm{pq}$ & 113802 & 493490 \\
\hline 34 & Planten & Huizen, erven, overig & $\mathrm{pq}$ & 116995 & 494848 \\
\hline 35 & Planten & Huizen, erven, overig & $\mathrm{pq}$ & 117689 & 493407 \\
\hline 86 & Planten & Stadsparken & $\mathrm{pq}$ & 115139 & 500160 \\
\hline 87 & Planten & Stadsparken & $\mathrm{pq}$ & 117949 & 493352 \\
\hline 88 & Planten & Stadsparken & $\mathrm{pq}$ & 117100 & 496043 \\
\hline 89 & Planten & Stadsparken & $\mathrm{pq}$ & 117160 & 498198 \\
\hline 90 & Planten & Stadsparken & $\mathrm{pq}$ & 112910 & 502081 \\
\hline 120 & Planten & Loofbos \& struweel & $\mathrm{pq}$ & 118656 & 493844 \\
\hline 121 & Planten & Loofbos \& struweel & $\mathrm{pq}$ & 119227 & 493657 \\
\hline 122 & Planten & Loofbos \& struweel & $\mathrm{pq}$ & 117098 & 497098 \\
\hline 123 & Planten & Loofbos \& struweel & $\mathrm{pq}$ & 117652 & 496895 \\
\hline 124 & Planten & Loofbos \& struweel & $\mathrm{pq}$ & 114211 & 502821 \\
\hline 238 & Planten & Moeras en vochtige ruigte & $\mathrm{pq}$ & 117237 & 496068 \\
\hline 239 & Planten & Moeras en vochtige ruigte & $\mathrm{pq}$ & 117656 & 496903 \\
\hline 263 & Planten & Droge rietlanden en ruigte & $\mathrm{pq}$ & 112769 & 498940 \\
\hline 264 & Planten & Droge rietlanden en ruigte & $\mathrm{pq}$ & 111371 & 499877 \\
\hline 265 & Planten & Droge rietlanden en ruigte & $\mathrm{pq}$ & 111380 & 499866 \\
\hline 266 & Planten & Droge rietlanden en ruigte & $\mathrm{pq}$ & 112541 & 494651 \\
\hline 267 & Planten & Droge rietlanden en ruigte & $\mathrm{pq}$ & 113934 & 493884 \\
\hline 346 & Planten & Kruidenrijk grasland & $\mathrm{pq}$ & 117702 & 499007 \\
\hline 347 & Planten & Kruidenrijk grasland & $\mathrm{pq}$ & 112383 & 494156 \\
\hline 348 & Planten & Kruidenrijk grasland & $\mathrm{pq}$ & 109996 & 494494 \\
\hline 349 & Planten & Kruidenrijk grasland & $\mathrm{pq}$ & 108783 & 495269 \\
\hline 350 & Planten & Kruidenrijk grasland & $\mathrm{pq}$ & 108672 & 496470 \\
\hline 369 & Planten & Plasdras & $\mathrm{pq}$ & 116205 & 499488 \\
\hline 370 & Planten & Plasdras & $\mathrm{pq}$ & 116173 & 499456 \\
\hline 371 & Planten & Plasdras & $\mathrm{pq}$ & 116326 & 499564 \\
\hline 385 & Planten & Wegberm & $\mathrm{pq}$ & 113028 & 498466 \\
\hline 386 & Planten & Wegberm & $\mathrm{pq}$ & 113860 & 498354 \\
\hline 387 & Planten & Wegberm & $\mathrm{pq}$ & 114295 & 493780 \\
\hline 388 & Planten & Wegberm & $\mathrm{pq}$ & 108839 & 495062 \\
\hline 389 & Planten & Wegberm & $\mathrm{pq}$ & 108653 & 498549 \\
\hline 405 & Planten & Agrarisch grasland & $\mathrm{pq}$ & 108513 & 497986 \\
\hline 406 & Planten & Agrarisch grasland & $\mathrm{pq}$ & 108660 & 498542 \\
\hline 407 & Planten & Agrarisch grasland & $\mathrm{pq}$ & 108833 & 499395 \\
\hline 408 & Planten & Agrarisch grasland & $\mathrm{pq}$ & 108946 & 500005 \\
\hline 409 & Planten & Agrarisch grasland & $\mathrm{pq}$ & 109310 & 500746 \\
\hline 420 & Planten & Spoorberm & $\mathrm{pq}$ & 118068 & 433254 \\
\hline 421 & Planten & Spoorberm & $\mathrm{pq}$ & 112787 & 500863 \\
\hline 422 & Planten & Spoorberm & $\mathrm{pq}$ & 115434 & 498279 \\
\hline 423 & Planten & Spoorberm & $\mathrm{pq}$ & 117412 & 496829 \\
\hline 424 & Planten & Spoorberm & $\mathrm{pq}$ & 117724 & 496913 \\
\hline 440 & Planten & Plantsoengras & $\mathrm{pq}$ & 117050 & 494694 \\
\hline 441 & Planten & Plantsoengras & $\mathrm{pq}$ & 116995 & 494848 \\
\hline 442 & Planten & Plantsoengras & $\mathrm{pq}$ & 117431 & 493769 \\
\hline 443 & Planten & Plantsoengras & $\mathrm{pq}$ & 116631 & 496351 \\
\hline 444 & Planten & Plantsoengras & $\mathrm{pq}$ & 116190 & 497027 \\
\hline 463 & Planten & Droog & $\mathrm{pq}$ & 113397 & 494241 \\
\hline 464 & Planten & Droog & $\mathrm{pq}$ & 112342 & 494073 \\
\hline 465 & Planten & Droog & $\mathrm{pq}$ & 113775 & 502331 \\
\hline 466 & Planten & Droog & $\mathrm{pq}$ & 113739 & 494163 \\
\hline 467 & Planten & Droog & $\mathrm{pq}$ & 114384 & 493324 \\
\hline 487 & Planten & Nat & $\mathrm{pq}$ & 118946 & 493142 \\
\hline 488 & Planten & Nat & $\mathrm{pq}$ & 116396 & 497471 \\
\hline 489 & Planten & Nat & $\mathrm{pq}$ & 113397 & 494241 \\
\hline 490 & Planten & Nat & $\mathrm{pq}$ & 114384 & 493324 \\
\hline
\end{tabular}




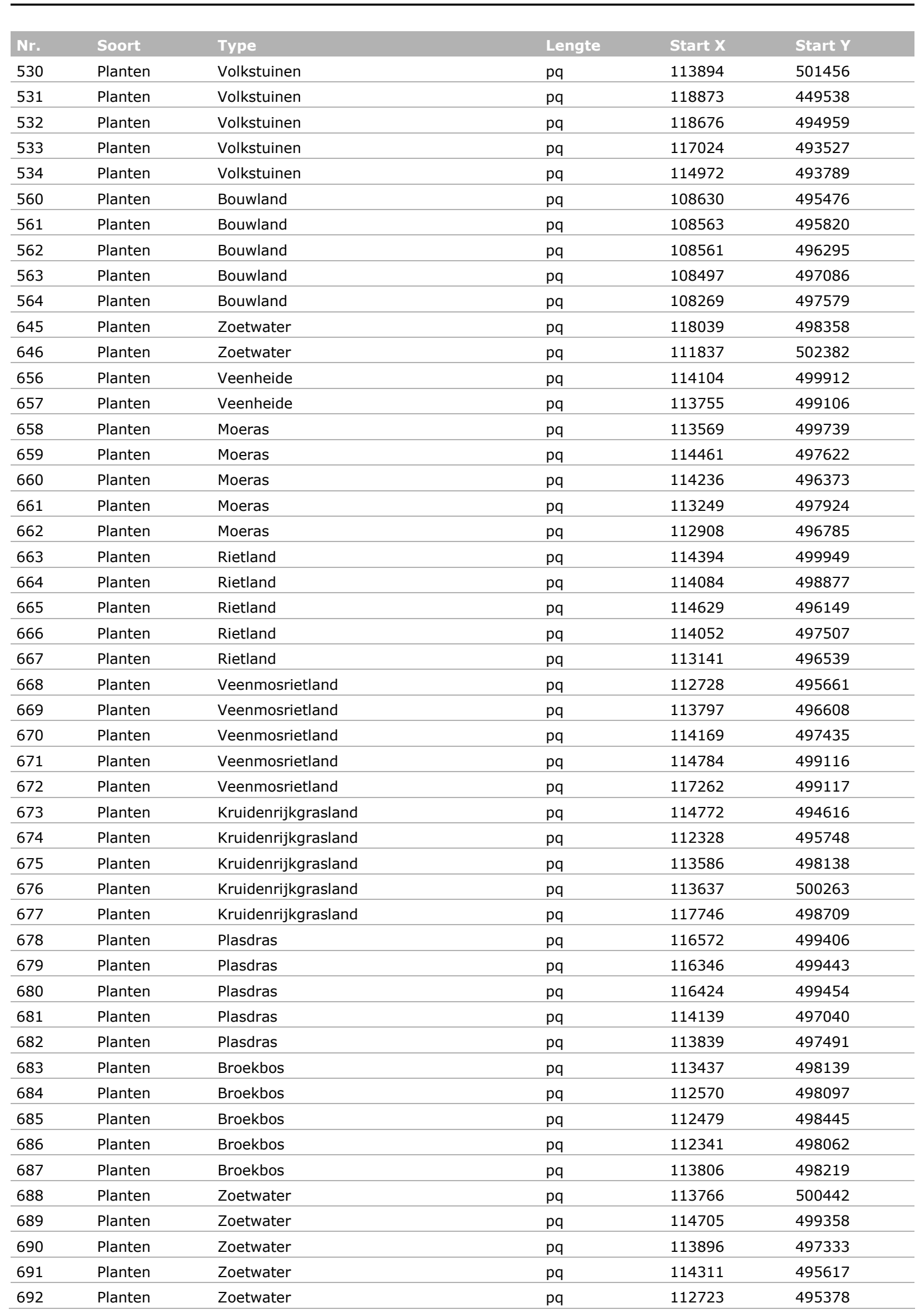



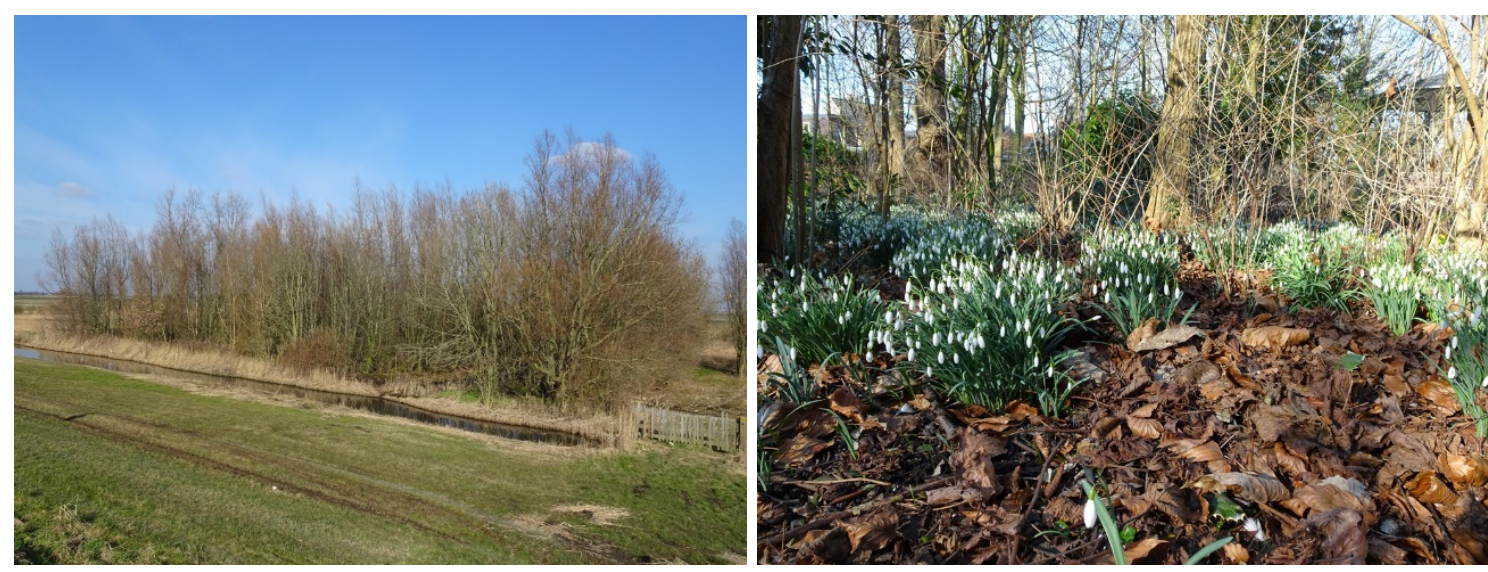

Figuur 27 Voorbeelden meetpunten in landschapstype 'Loofbos en struweel' (links) en 'Stadsparken' (rechts). 


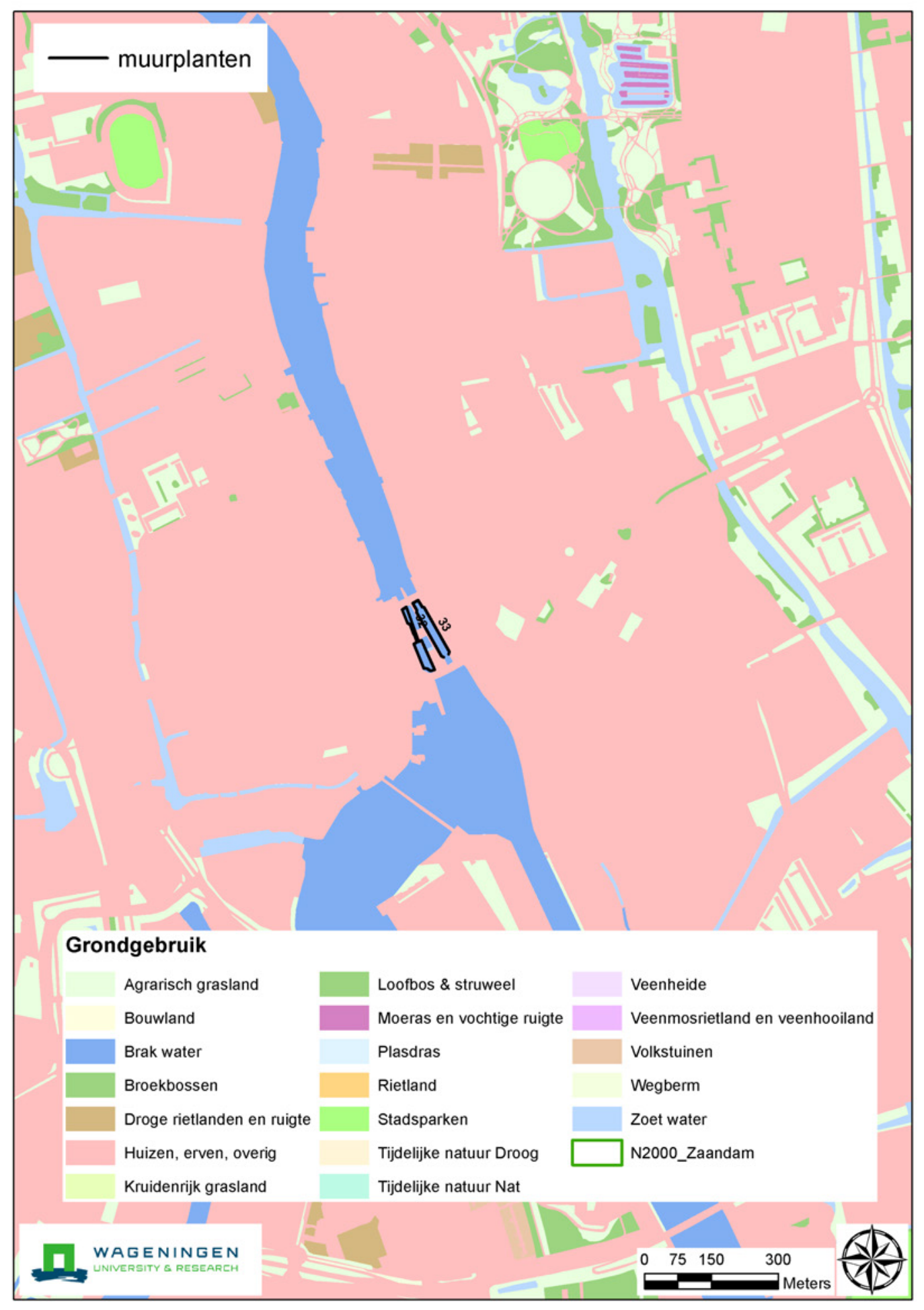

Figuur 28 Meetpunten voor muurplanten. 


\section{Tabel 15 Meetpunten voor muurplanten.}

\begin{tabular}{llllllll} 
Nr. & Soort & Type & Lengte & Start X & Start Y & Eind X & Eind Y \\
\hline 32 & Planten & Huizen, erven, overig & $300(298)$ & 116805 & 494714 & 116805 & 494714 \\
\hline 33 & Planten & Huizen, erven, overig & $300(345)$ & 116853 & 494746 & 116842 & 494739 \\
\hline
\end{tabular}
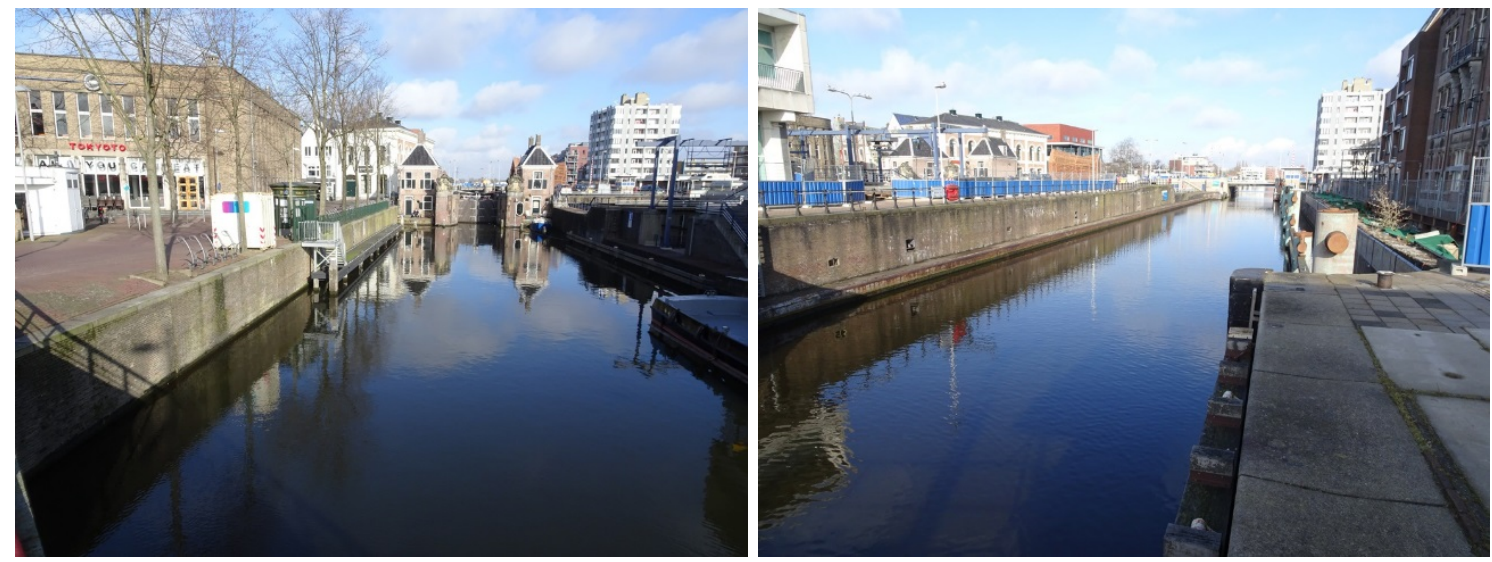

Figuur 29 Voorbeelden meetpunten in landschapstype links 'Huizen, erven, overig', in dit geval kademuren voor muurplanten. 


\section{Literatuur}

Ottburg, F.G.W.A., D.R. Lammertsma en R.M.A. Wegman, 2018. Meetnet Biodiversiteit Zaanstad.

Wageningen, Wageningen Environmental Research, Rapport 2866. 58 blz.; 7 fig.; 13 tab.; 21 ref.

Veer, R. van 't, T. Kisjes en N. Sminia, 2012. Natuuratlas Zaanstad. Stichting uitgeverij NoordHolland. 
Wageningen Environmental Research Postbus 47

6700 AA Wageningen

T 0317480700

www.wur.nl/environmental-research

Wageningen Environmental Research Rapport 2885

ISSN 1566-7197
De missie van Wageningen University \& Research is 'To explore the potential of nature to improve the quality of life'. Binnen Wageningen University \& Research bundelen Wageningen University en gespecialiseerde onderzoeksinstituten van Stichting Wageningen Research hun krachten om bij te dragen aan de oplossing van belangrijke vragen in het domein van gezonde voeding en leefomgeving. Met ongeveer 30 vestigingen, 5.000 medewerkers en 10.000 studenten behoort Wageningen University \& Research wereldwijd tot de aansprekende kennisinstellingen binnen haar domein. De integrale benadering van de vraagstukken en de samenwerking tussen verschillende disciplines vormen het hart van de unieke Wageningen aanpak. 



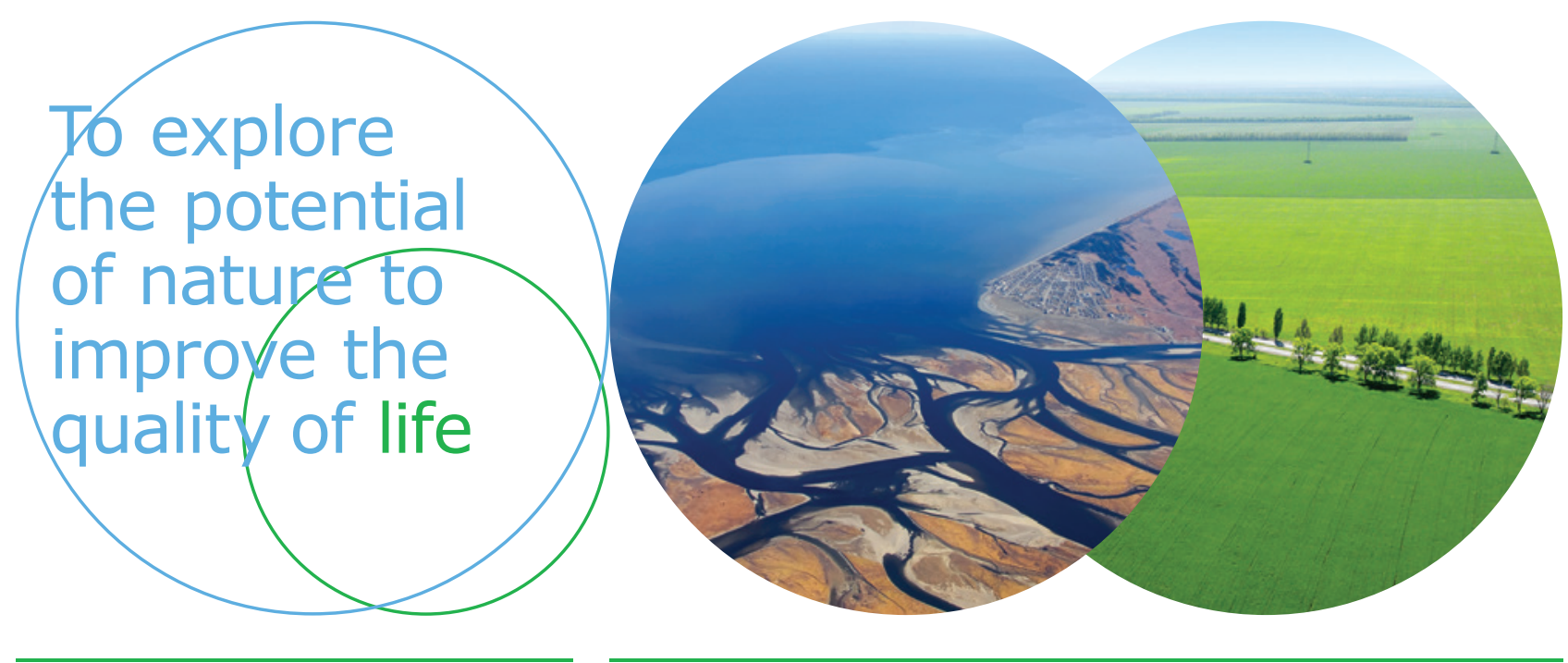

Wageningen Environmental Research Postbus 47

$6700 \mathrm{AB}$ Wageningen

T 317480700

www.wur.nl/environmental-research

Rapport 2885

ISSN 1566-7197
De missie van Wageningen University \& Research is 'To explore the potential of nature to improve the quality of life'. Binnen Wageningen University \& Research bundelen Wageningen University en gespecialiseerde onderzoeksinstituten van Stichting Wageningen Research hun krachten om bij te dragen aan de oplossing van belangrijke vragen in het domein van gezonde voeding en leefomgeving. Met ongeveer 30 vestigingen, 5.000 medewerkers en 10.000 studenten behoort Wageningen University \& Research wereldwijd tot de aansprekende kennisinstellingen binnen haar domein. De integrale benadering van de vraagstukken en de samenwerking tussen verschillende disciplines vormen het hart van de unieke Wageningen aanpak. 